\title{
Vibration-based tool wear monitoring using Artificial Neural Networks fed by Spectral centroid indicator \& RMS of CEEMDAN modes
}

Mourad NOUIOUA ( $\square$ nouiouamourad25@yahoo.fr)

Universite 8 Mai 1945 Guelma https://orcid.org/0000-0003-0439-2112

Mohamed Lamine BOUHALAIS

Universite 8 Mai 1945 Guelma

\section{Research Article}

Keywords: CEEMDAN, RMS, Tool wear, ANN, Vibration

Posted Date: April 2nd, 2021

DOl: https://doi.org/10.21203/rs.3.rs-357733/v1

License: (c) (i) This work is licensed under a Creative Commons Attribution 4.0 International License.

Read Full License 


\title{
Vibration-based tool wear monitoring using Artificial Neural Networks fed by Spectral centroid indicator \& RMS of CEEMDAN modes
}

\author{
*Mourad NOUIOUA ${ }^{1}$, Mohamed Lamine BOUHALAIS ${ }^{1}$ \\ ${ }^{1}$ Mechanics Research Centre. Po, Box 73B, 25000 CONSTANTINE, ALGERIA. \\ *Corresponding Author: nouiouamourad25@yahoo.fr
}

\begin{abstract}
In machining processes various phenomena occur during cutting operation. These phenomena can disturb the production through the reduction of part quality and accuracy. Therefore, a mastery of this cutting phenomena is needed to define the machining parameters and take full advantage of manufacturing process. An easy way to classify these phenomena is by monitoring incontrollable parameters, such as generated temperature and vibration. The acquired vibration signals can provide information regarding tool life, cutting performances and workpiece defects. This paper evaluates the possibility of monitoring the tool life during the turning process of AISI 1045 steel using Laser Doppler Vibrometer (LDV), the surface roughness has been measured along with the tool-wear until reaching its limit value of $300 \mu \mathrm{m}$. Furthermore, this paper also outlines the application of CEEMDAN technique to process the acquired signals for the monitoring processes. RMS and SCI indicators have been used to describe the wear progress, then, the artificial neural network has been adopted to achieve a real time wear monitoring. The obtained results qualified the SCI indicator and ANN for online monitoring.
\end{abstract}

Keywords: CEEMDAN, RMS, Tool wear, ANN, Vibration. 


\section{Introduction}

Tool wear through machining processes is recognized by changing the geometry of the cutting tool, thus increasing cutting force, affecting surface finish and may disturb dimensional accuracy of the workpiece. The monitoring of machining processes can represent economy and practicality due to it use for identifying tool wear sate, surface roughness, and anomalies during the cutting operation that can cause waste, damage, and other impairing factors in this process [1]. The tool wear monitoring is complex and should deliver a notification of when the cutting insert should be replaced to avoid any change in the workpiece surface finish, the machine integrity, and the manufactured parts tolerances [2]. However, to acquire these advantages it is necessary to guarantee that the cutting set up is in perfect order.

Vibration is a common phenomenon in the finishing machining especially during turning of a flexible workpiece because of its low rigidity [3]. The interest of industrials is to avoid the vibrations that results bad surface quality and may defects the machining mechanisms [4]. In this context Shahabi \& M. Ratnam [5] tried to monitor the wear using High-resolution CCD camera, they found that the developed control system is influenced by several incontrollable factors such as the work environment, misalignment of cutting tool, presence of micro-dust particles, vibration and intensity variation of ambient light. Other authors used the intelligent image processing for tool wear monitoring [6], whereas, Wan-Hao Hsieh et al. [7] used the vibration of the spindle for the monitoring system.

Babouri et al. [8] proposed the Wavelet Multi-Resolution Analysis to improve the sensitivity of the vibration scalar indicators for the identification of the wear state during the machining of $\mathrm{X} 200 \mathrm{Cr} 12$ steel, they have proven that there is a possibility to associate the tool wear with the vibration generated when machining. In another study [9], they used a spectral indicator named spectral center of gravity (SCG) to highlight the three phases of tool wear, they applied the spectral center of gravity to quantify the changes of the tool natural frequencies amplitudes that result from the evolution of tool wear. Their obtained results are very promising for industrial application. Rao et al. [10] used the vibration analysis in the turning of AISI1040 tube, outer diameter of $100 \mathrm{~mm}$ and inner diameter of $56 \mathrm{~mm}$ using a tool with nose radius of 0.8 and $0.4 \mathrm{~mm}$ under dry conditions. Among the several observations, vibration amplitudes were found to increase with the progression of tool wear.

In wear detection using vibration analysis, Issam Abu-Mahfouz [11] adopted the artificial neural network for tool condition monitoring. The results indicated that the averaged 
harmonic wavelet coefficients and the maximum entropy spectrum peaks, are more efficient in training the neural network than the time domain statistical moments. For the online monitoring, Maohua Du et al. [12] investigated an intelligent, real-time and visible tool state monitoring based on LabVIEW and MATLAB hybrid programming, their results showed that the correct recognition rate of the network model after samples training is $92.59 \%$, which can more accurately and intelligently monitor the tool wear state. Other researchers strained the Inprocess tool wear monitoring using deep learning [13] their results showed that the proposed model was more robust and accurate for tool wear prediction.

Artificial Neural networks and its variants are among the most commonly used approaches in tool wear assessment [14-15]. In several papers, extensions of ANNs have been used and adapted to achieve higher performance in diverse cutting conditions for wear monitoring [16]. Some researchers tried to take the advantage of various sensors to improve the accuracy of the wear estimation algorithms [17]; however, it did not guarantee the enhancement of the estimations.

In order to enhance the monitoring technics for wear classification in machining process, the current study investigates the monitoring possibility of the cutting tool life when turning of AISI 1045 steel with TNMG carbide insert. the cutting speed (Vc), feed rate (f) and the depth of cut (ap) are fixed to be $300 \mathrm{~m} / \mathrm{min}, 0.034 \mathrm{~mm} / \mathrm{rev}$ and $0.15 \mathrm{~mm}$ respectively during all the investigation to explore the vibration significance. The measuring system used for the experiment is an LDV scanner (Laser Doppler Vibrometer) for non-contact acquisition where the laser beam has been focused at the tool holder, and configured to follow the feed motion of the tool during the cutting operation which provide a real time vibration signal, the acquired signal has been analyzed using the Complete Ensemble Empirical Mode Decomposition with Adaptive Noise (CEEMDAN) approach to be able to study just the frequencies domain that contains more information regarding the development of the wear. After that, RMS and SCI indicators have been calculated for the selected Intrinsic mode function (IMF) from the CEEMDAN decomposition of the twenty-one runs and explore the information that could help us to monitor the tool life regarding the measured wear values. In addition, the surface roughness has been measured and evaluated with respect to the intensity of the vibrations and the state of wear. Finally, the integration of the Artificial Neural Networks has been done for forecasting the tool life. The monitoring process has been achieved as indicated in figure 1 . 


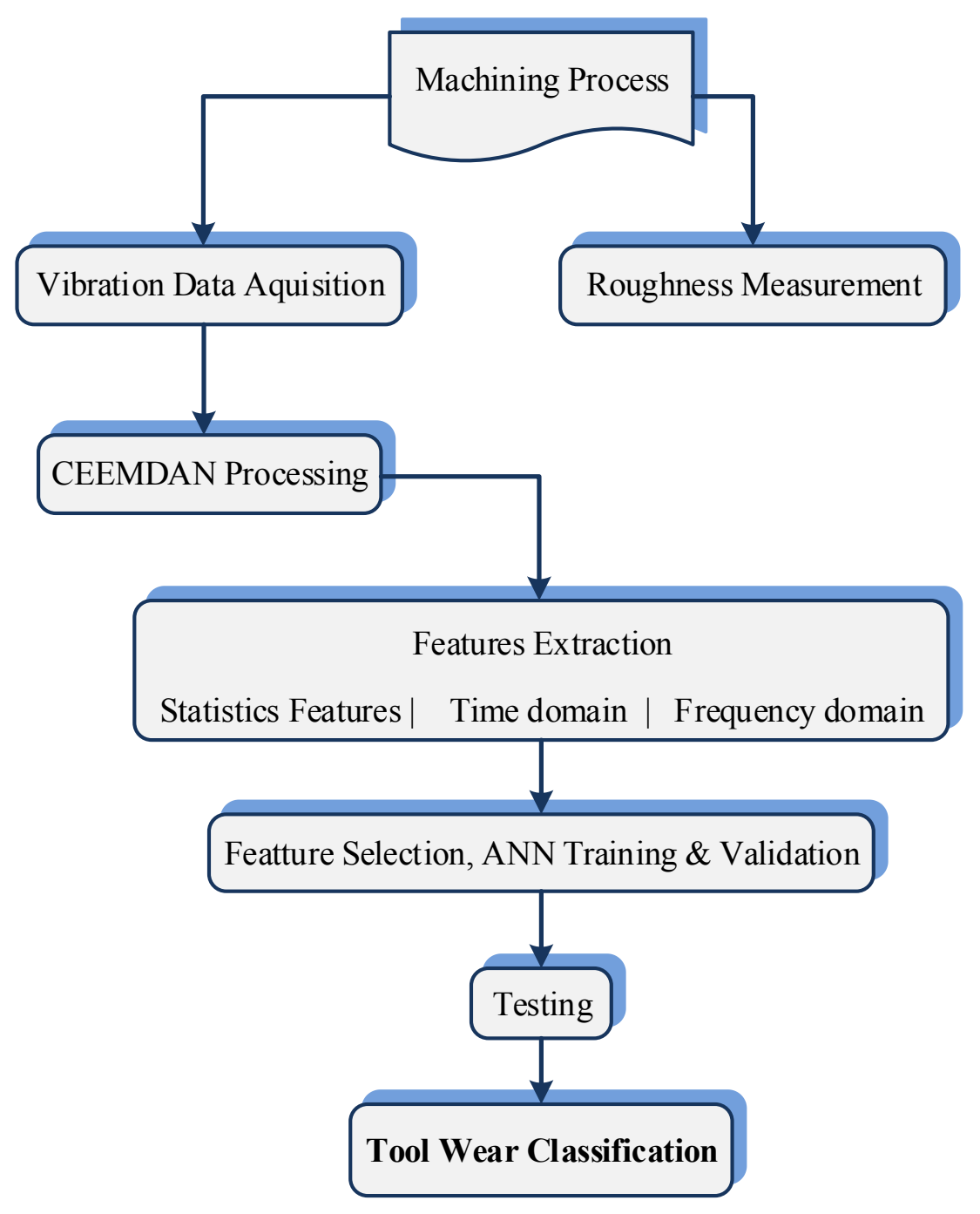

Figure 1. Flow chart of the tool life monitoring method.

\section{Complete Ensemble EMD with Adaptive Noise}

The CEEMDAN is developed from the EEMD. To alleviate the mode mixing problem, the white Gaussian noise which having a certain standard deviation is adopted. By adding the limited number of the adaptive white noise at each decomposition, the CEEMDAN needs less experiments than the EEMD. In addition, since the decomposition and rebuilding of the CEEMDAN are complete, the CEEMDAN can overcome the mode mixing problem [18].

For the decomposition of a given signal $x(t)$ with CEEMDAN, the below steps are followed:

1. Decompose $I$ realizations of $x(t)+\varepsilon_{0} n^{i}(t)$ by EMD to obtain the first $\overline{I M F_{1}}$ by averaging: 


$$
\overline{I M F_{1}(t)}=\frac{1}{I} \sum_{i=1}^{I} I M F_{1}^{i}(t)
$$

2. Calculate the first residue as:

$$
r_{1}(t)=x(t)-\overline{I M F_{1}(t)}
$$

3. Decompose $I$ realizations of $r_{1}(t)+\varepsilon_{1} E_{1}\left(n^{i}(t)\right)$ until their first EMD mode and calculate the second mode:

$$
\overline{I M F_{2}(t)}=\frac{1}{I} \sum_{i=1}^{I} E_{1}\left(r_{1}(t)+\varepsilon_{1} E_{1}\left(n^{i}(t)\right)\right)
$$

Where $E_{j}$ is an operator that produces the $j^{\text {th }}$ mode obtained by EMD.

4. For $k=2 \ldots . K$, calculate the $k$-th residue:

$$
r_{k}(t)=r_{k-1}(t)-\overline{I M F_{k}(t)}
$$

5. For $k=2 \ldots . K$, define the $(k+1)$-th mode as:

$$
\overline{I M F_{k+1}(t)}=\frac{1}{I} \sum_{i=1}^{I} E_{1}\left(r_{k}(t)+\varepsilon_{k} E_{k}\left(n^{i}(t)\right)\right)
$$

6. Go for step 4 for next $k$

Steps from 4 to 6 are repeated until the obtained residue in no longer feasible to be decomposed and satisfies:

$$
R(t)=x(t)-\sum_{k=1}^{K} \overline{I M F_{k}}(t)
$$

With $K$ the total number of modes. The original signal $x(t)$ can be expressed in the end as:

$$
x(t)=\sum_{k=1}^{K} \overline{I M F_{k}}(t)+R(t)
$$

\section{Experimental setup}

The experimental conditions and cutting parameters are set according to different aspects such as (the material to be machined, the machine tool and cutting tool) [19]. In this experimental work, the tests have been carried out using a conventional lathe "KNUTH TURNADO". The workpiece material is the AISI 1045 steel. The properties of the latter are defined in the table 1 , 
Table 1 Chemical composition of AISI 1045 Steel.

\begin{tabular}{|l|l|}
\hline Element & Content \\
\hline Carbon, C & $0.420-0.50 \%$ \\
\hline Iron, Fe & $98.51-98.98 \%$ \\
\hline Manganese, Mn & $0.60-0.90 \%$ \\
\hline Phosphorous, P & $\leq 0.040 \%$ \\
\hline Sulfur, S & $\leq 0.050 \%$ \\
\hline
\end{tabular}

The challenge for real-time monitoring is the positioning of the sensors because depending on the application the sensors cannot be used, especially when using cutting fluid.

The vibration measurement in this study was performed using a non-contact Laser Doppler Vibrometer (LDV). The laser beam from the LDV is directed to the surface of interest on the holder. The vibratory amplitudes and frequencies were extracted from the Doppler shift of the reflected laser beam due to the movement of the tool holder surface. The scanner has been configured to follow the toolholder motion at the same speed (feed rate). As for the cutting tool, the TNMG carbide insert was used for the machining tests. The schematic diagram of the experimental set up is shown figure 2 .

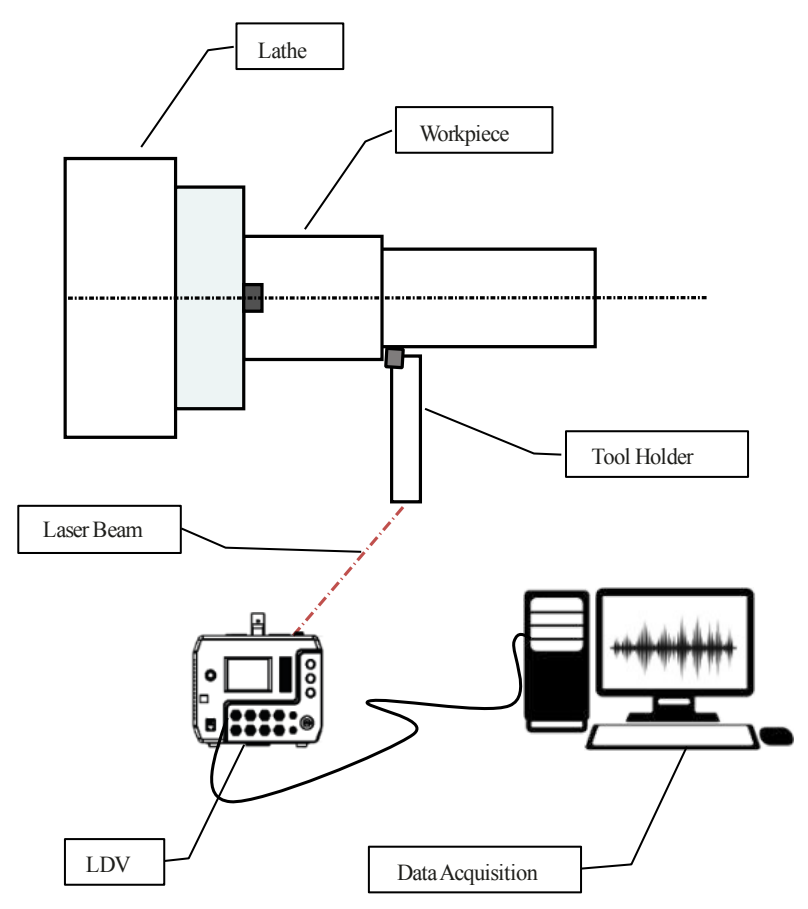

Figure 2. Experimental set up for monitoring system and data analysis. 
Regarding the surface roughness, the measurements were taken directly after each test using a roughness meter (PCE-RT 1200) which consists of a diamond tip (probe). While the wear values have been measured after each run using Optika B-500 Microscope. The wear tests were carried out at a cutting speed (Vc) of $300 \mathrm{~m} / \mathrm{min}$, cutting depth (ap) of $0.15 \mathrm{~mm}$ and a feed rate (f) of $0.034 \mathrm{~mm} / \mathrm{rev}$ while the length of each machining run is $150 \mathrm{~mm}$.

\section{Results and Analysis}

\section{Wear and surface roughness analysis}

In General, the flank wear (VB) is the most used factor to assess cutting tool life. Its progress regarding the machining time passes through three phases: initial wear phase, wear stabilization and accelerated wear as illustrated in figure 3.

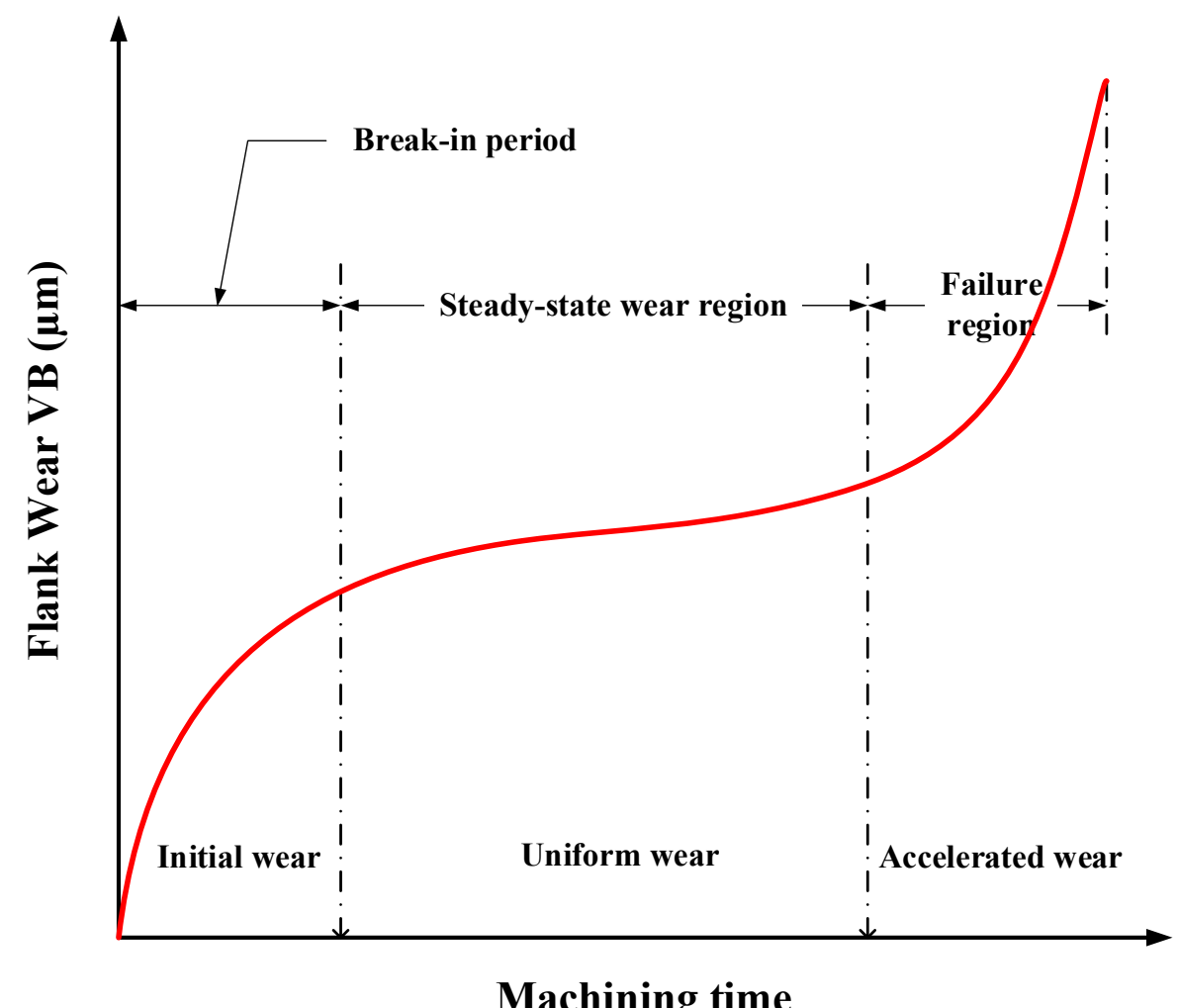

Figure 3. Theoretical tool wear.

The life time of a cutting tool is influenced by a range of incontrollable factors. At high speeds, the contact surface of the tool-workpiece generate latter a quantity of heat which alters the cutting edges by complex physicochemical phenomena [20]. The tool-life is characterized by the time taken to reach the limit value of the wear criterion considered in specific cutting 
conditions. The limit wear value taken in this study is $300 \mu \mathrm{m}$. The experimental results are given in table 2.

Table 2. The experimental results

\begin{tabular}{ccc}
\hline \multirow{2}{*}{ Run Order } & \multicolumn{2}{c}{ Response Factors } \\
\cline { 2 - 3 } 1 & $R a(\mu m)$ & $V B(\mu m)$ \\
\cline { 2 - 3 } 2 & 0.815 & 52.078 \\
3 & 0.713 & 100.005 \\
4 & 0.790 & 127.234 \\
5 & 1.340 & 135.4 \\
6 & 1.302 & 148.911 \\
7 & 1.362 & 161.992 \\
8 & 0.933 & 171.818 \\
9 & 0.760 & 180.751 \\
10 & 0.757 & 184.9 \\
11 & 1.318 & 193.082 \\
12 & 1.218 & 202.9 \\
13 & 1.014 & 206.179 \\
14 & 1.650 & 220.905 \\
15 & 1.677 & 230.006 \\
16 & 2.277 & 232.353 \\
17 & 2.273 & 233.989 \\
18 & 2.413 & 237.284 \\
19 & 1.787 & 247.085 \\
20 & 2.103 & 250.357 \\
21 & 2.377 & 294.536 \\
& 1.647 & 320.594 \\
\hline
\end{tabular}

The present study aims to determine the relationship between vibration and wear of the cutting tool, also to assess the possibility of monitoring the life of the cutting insert using noncontact vibration measurements. 


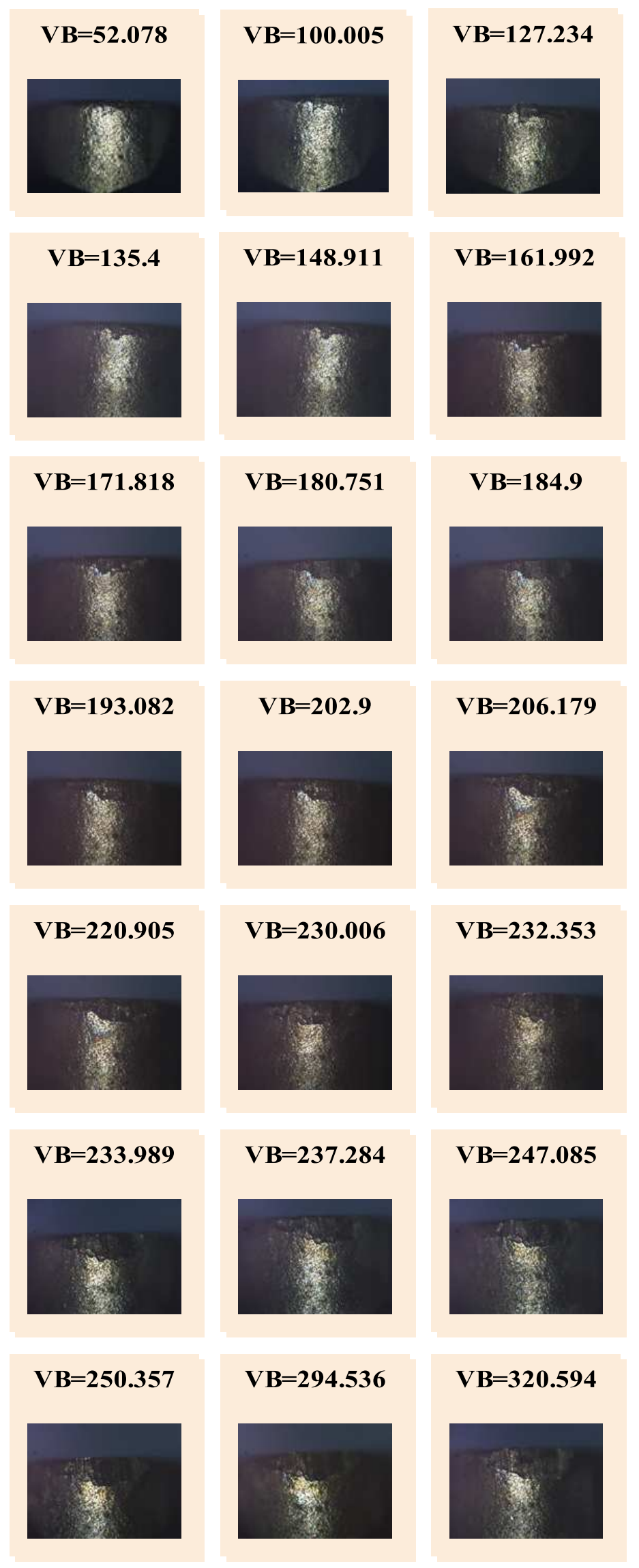

Figure 4. Wear Morphology from test of the cutting insert. 
The figure 4 illustrates the wear morphology, and figure 5 illustrates its evolution as function of machining time, the analysis of this figure shows that the rate of wear obeys the universal law of wear of any cutting tool. Regarding the surface roughness, the surface generated by the motion of the cutting edge of the tool has helical grooves resulting from the pointed shape of the tool.

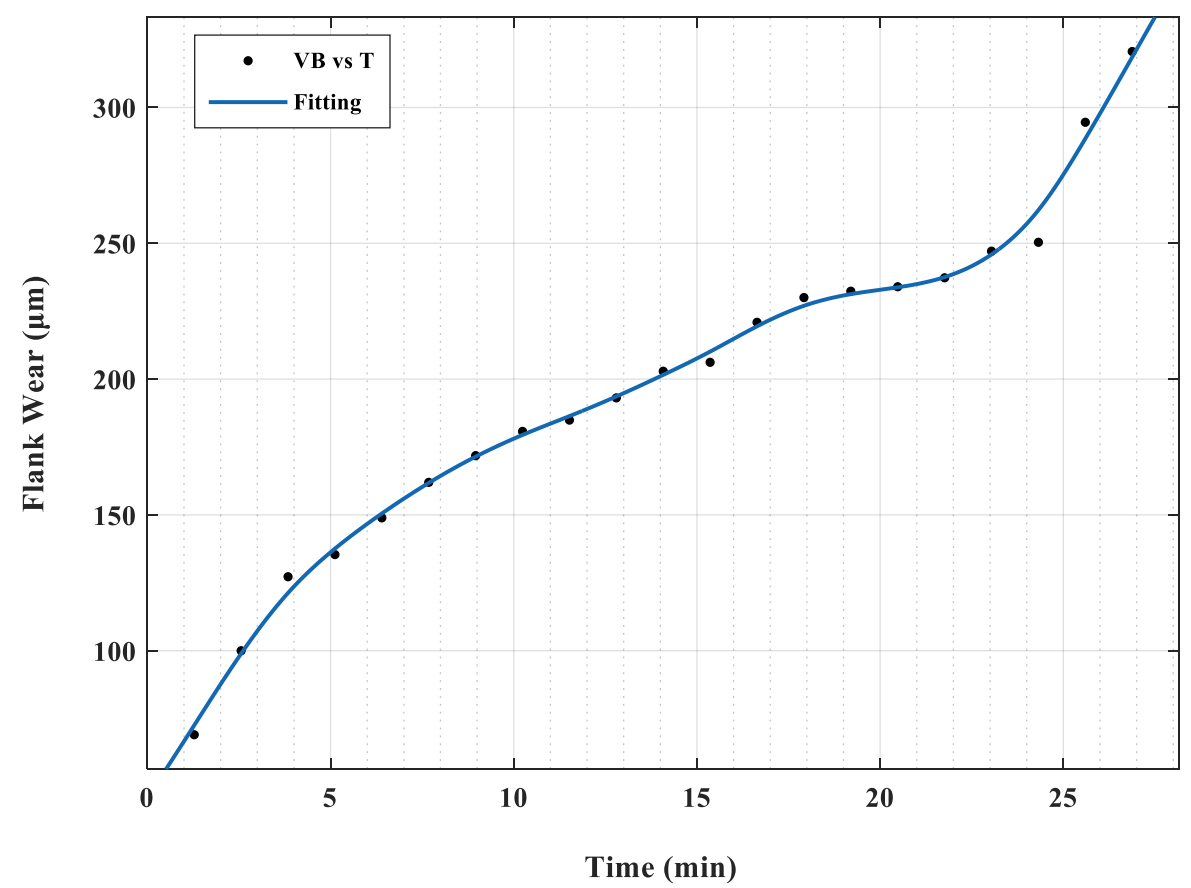

Figure 5. Wear Evolution Vs machining time

Indeed, the state of the tool-nose and the surface defects resulting the cutting imperfections and crater wear and gives a different surface roughness of the theoretical roughness. This difference is more or less sensitive depending on the operating conditions such as workpiece material, cutting speed and feed, type of tool and its wear, time and machining length. Also, any increases in flank wear $V_{B}$ result a corresponding deterioration in the machined surface. At this point, it is required to specify that, as long as wear is regular and does not exceed the tolerable limit, roughness (and in specific Ra) may increase gradually and the surface quality remains acceptable. [21].

The surface roughness is considered as one of the most critical constraints for the selection of cutting parameters in the planning of the machining process [22]. The figure 6 shows the obtained surface roughness for the twenty-on runs. At the beginning, the first three runs reveal that the surface state is smooth due to low wear rate of the cutting edge. After, the 
surface roughness fluctuates randomly according to the obtained tool geometry after each wear state. Taking for example: the Ra value of the test 8 in which the surface quality has undergone an improvement, the cutting edge become large resulting a crushing of asperities generating better surface quality.

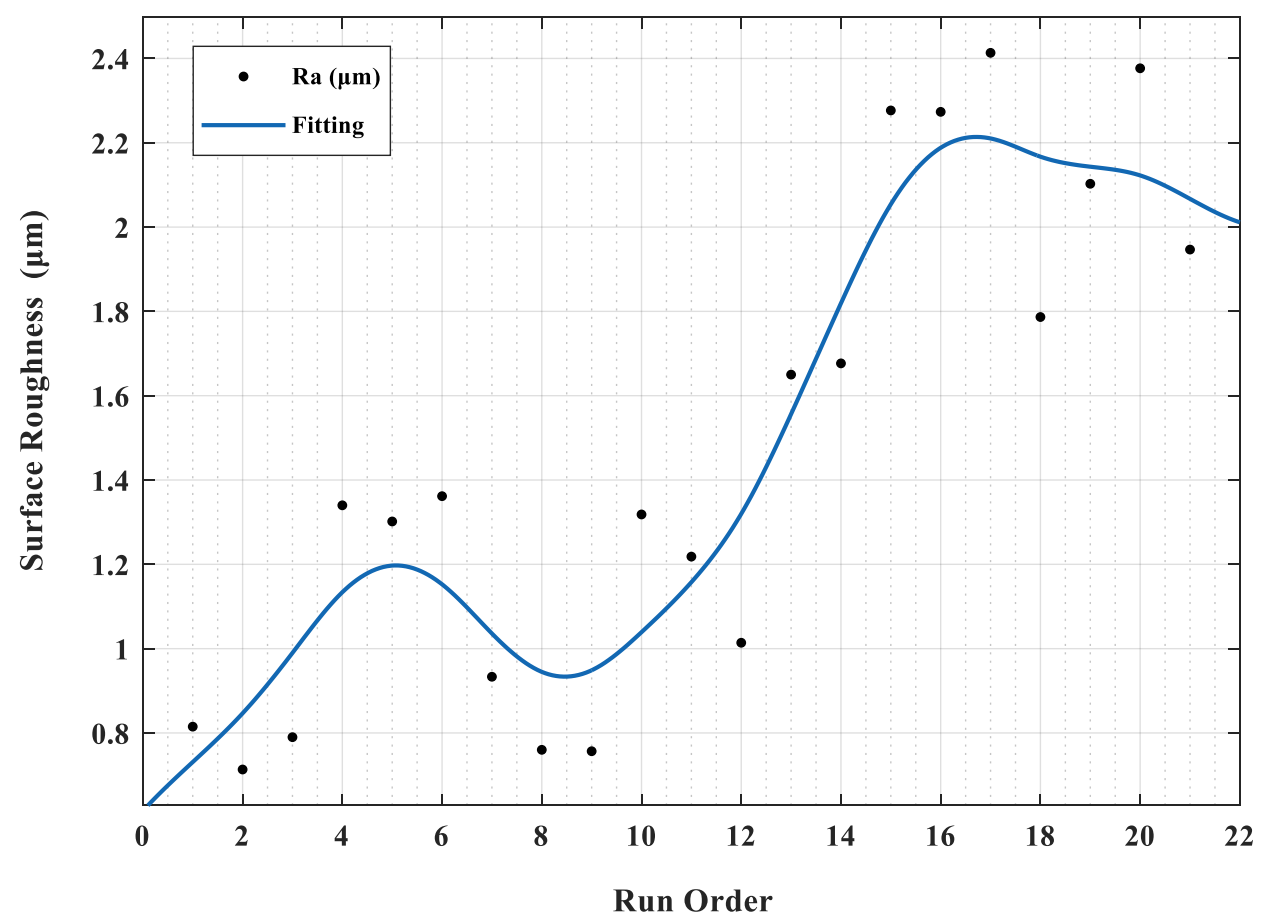

Figure 6. Surface roughness Vs. experimental run order

When the flank wear arrives to its accelerated phase, the surface quality becomes worst because the cutting insert loses its original cutting geometry, providing new contact surface which influences the general behavior of the machining process.

\section{Vibration Analysis}

The vibration signals acquired during machining are used to evaluate the possibility of monitoring the evolution of cutting tool-wear, from the evolution of various relevant parameters. For every machining run, the LDV is configured to scan 60 signals, every signal was recorded for $1.28 \mathrm{~s}$ which is equivalent to $27 \mathrm{~min}$ of the total machining time to achieve the limit wear value.

The Figure 7 shows the autospectrum of a free machining run having the same cutting speed and feed rate excluding the depth of cut. The purpose of this free test is to eliminate the vibration frequencies associated to the machine without the cutting operation. 


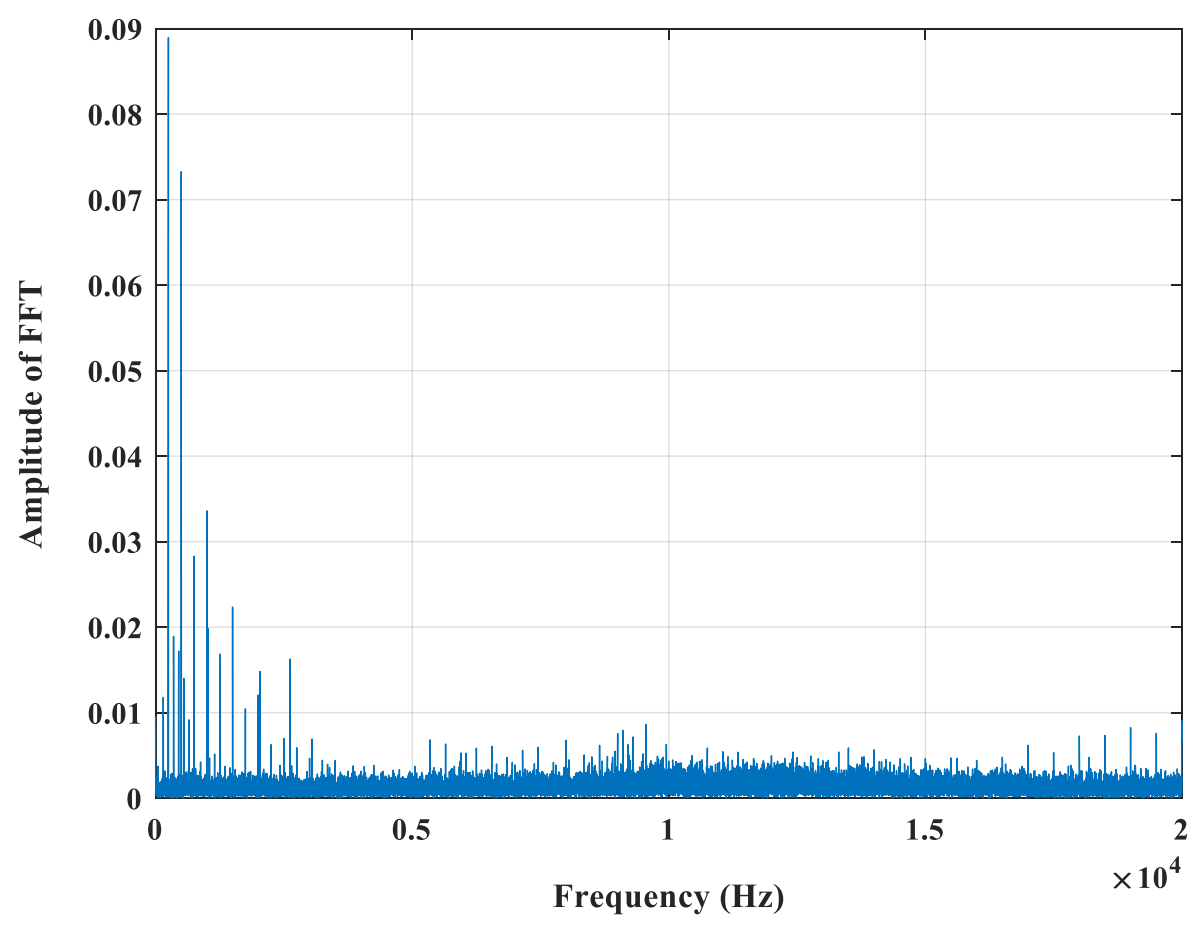

Figure 7. Free run spectrum.

The figure 8 shows the obtained autospectrum of the twenty-one runs, as illustrated the frequency behavior from 0 to $5000 \mathrm{~Hz}$ is same as in the free test, which indicates that these frequencies have no relation with the machining operation. Otherwise, the band of [5000 20000] can be considered for the wear analysis inasmuch as the magnitude variation noted in the twenty-one runs.

But, by comparing the different spectrums, there are some visual features typical for each machining run, A visualization of the autospectrum signals in figure 8 indicates that the amplitude of the Autospectrum increases with the wear till the $15^{\text {th }}$ run and subsides after the $16^{\text {th }}$ run. 

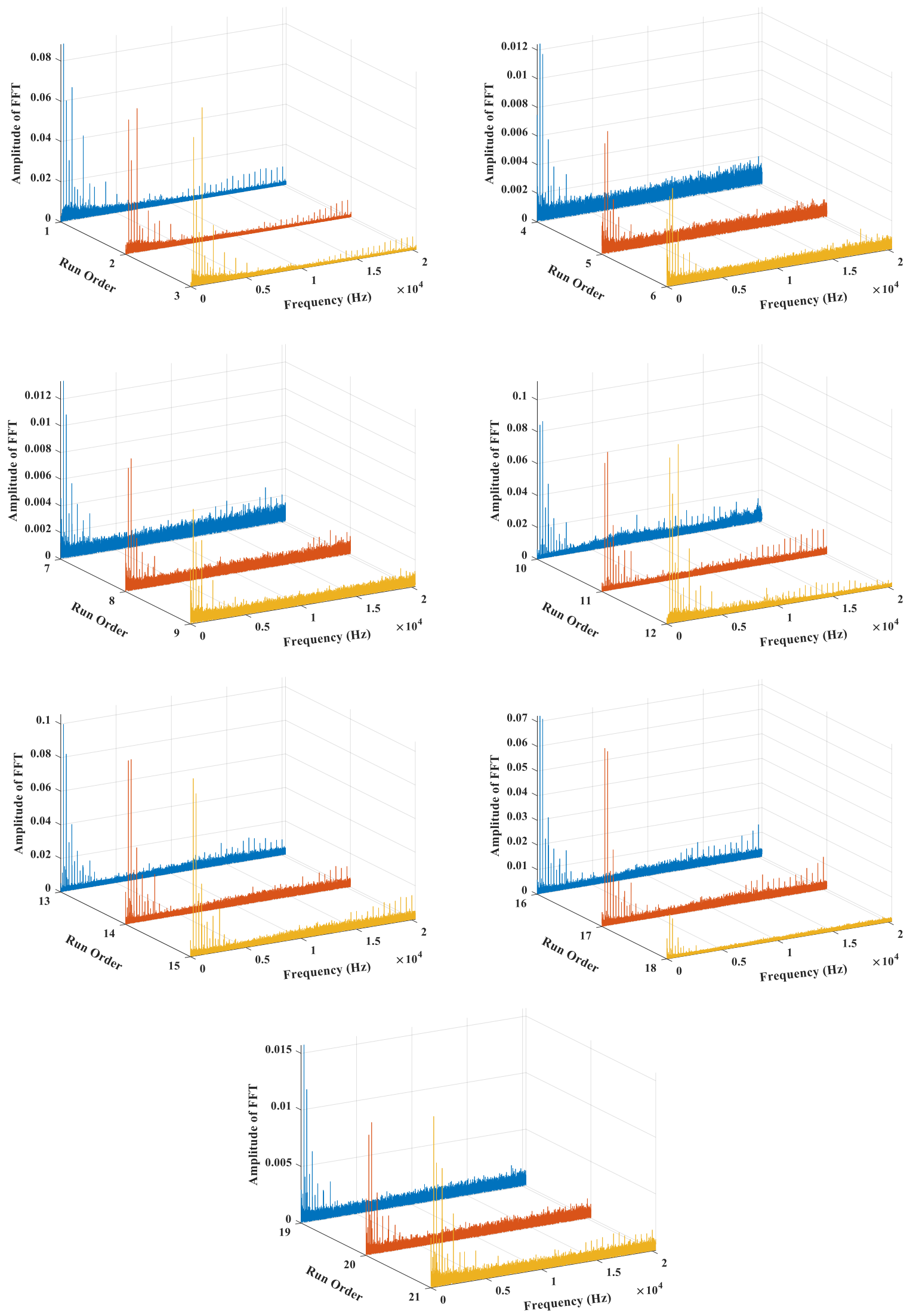

Figure 8. Autospectrum of the twenty-one runs. 
It is noticed that there is a random change in the amplitude that resembles the behavior of surface roughness, due to the new geometry of the cutting tool after reaching such wear state. In this case, it is hard to specify a rule that characterizes the vibration behavior in turning operation as regards wear and surface roughness.

CEEMDAN has been introduced to decompose the original vibration signals into a collection of IMFs with corresponding frequencies in order to locate the study in the band of [5000 20000]. Figure 9 shows an example of CEEMDAN decomposition results of the first vibratory signal, which is decomposed into seventeen IMFs, then the first IMF has been selected because it covers the considered band for the study. This work proposes this extraction method and use of following statistical features from IMFs to evaluate the tool-wear.

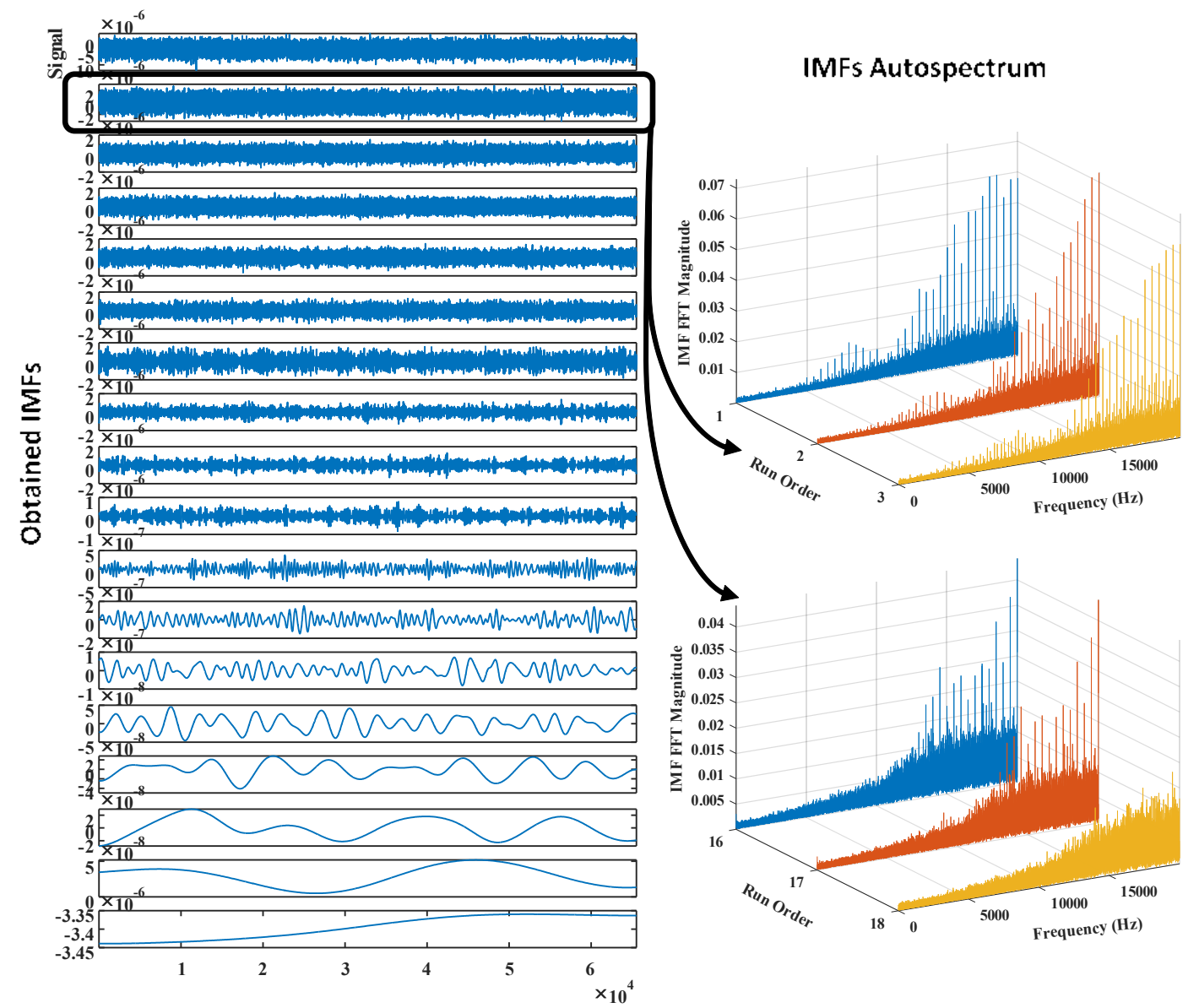

Figure 9. CEEMDAN decomposition.

\section{Root mean square (RMS)}

RMS values of vibration signals can be used to monitor the overall vibration level of a system. This is because the overall vibration level typically increases as the system deteriorates. 
If time series data of vibration signals are expressed as $\mathrm{x}(\mathrm{n})$, with $\mathrm{n} 1 / 41,2,3 \ldots \mathrm{N}$, where $\mathrm{N}$ is number of data points in a signal, RMS can be calculated as [23]:

$$
R M S=\sqrt{\frac{\sum_{n=1}^{N}(x(n))^{2}}{N}}
$$

The RMS values represented in figure 10 calculated from the twenty-one IMFs are showing partial increasing trend with the wear state in the wear stabilization phase, otherwise, the critical stage of wear cannot be defined using this indicator. In this case, RMS couldn't provide the enough information that concern the real-time wear state.

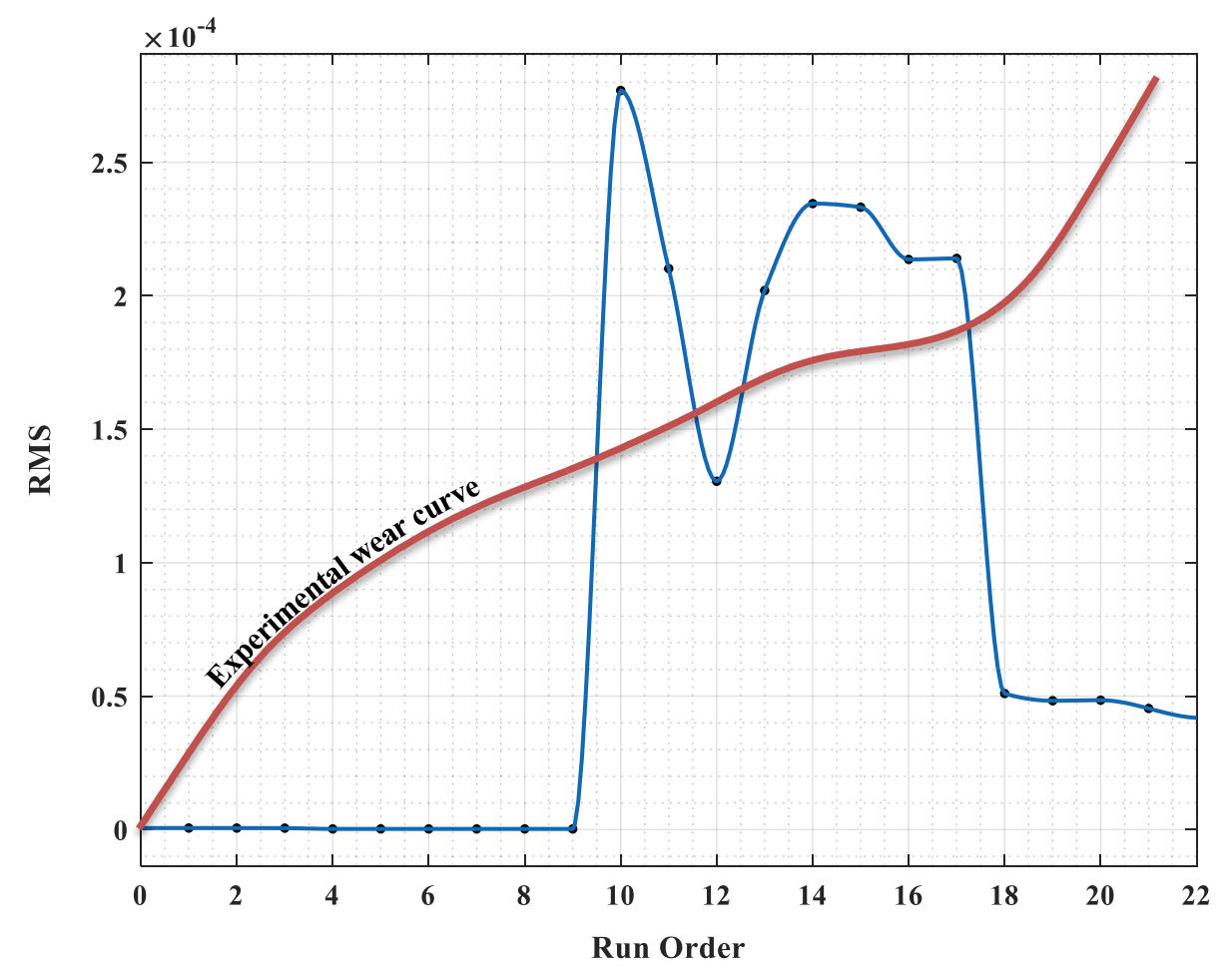

Figure 10. Obtained RMS for the twenty-one signals.

\section{Spectral Centroid Indicator (SCI)}

In order to simplify the monitoring process for industrial application, an evaluation of the use of spectral centroid as a scalar indicator has been established. The SCI has been calculated from the IMFs of the acceleration signals measured to identify the failure wear phase.

The spectral Centroid is generally used for audio signals, as well as for the examination of automobiles and traffic noise. The expression of the spectral centroid is given by the following equation [24]: 


$$
\text { Centroid }=\frac{\sum_{k=n}^{N} f_{k} s_{k}}{\sum_{k=n}^{N} s_{k}}
$$

Where:

- $f_{k}$ is the frequency in Hz.

- $\quad s_{k}$ is the spectral value.

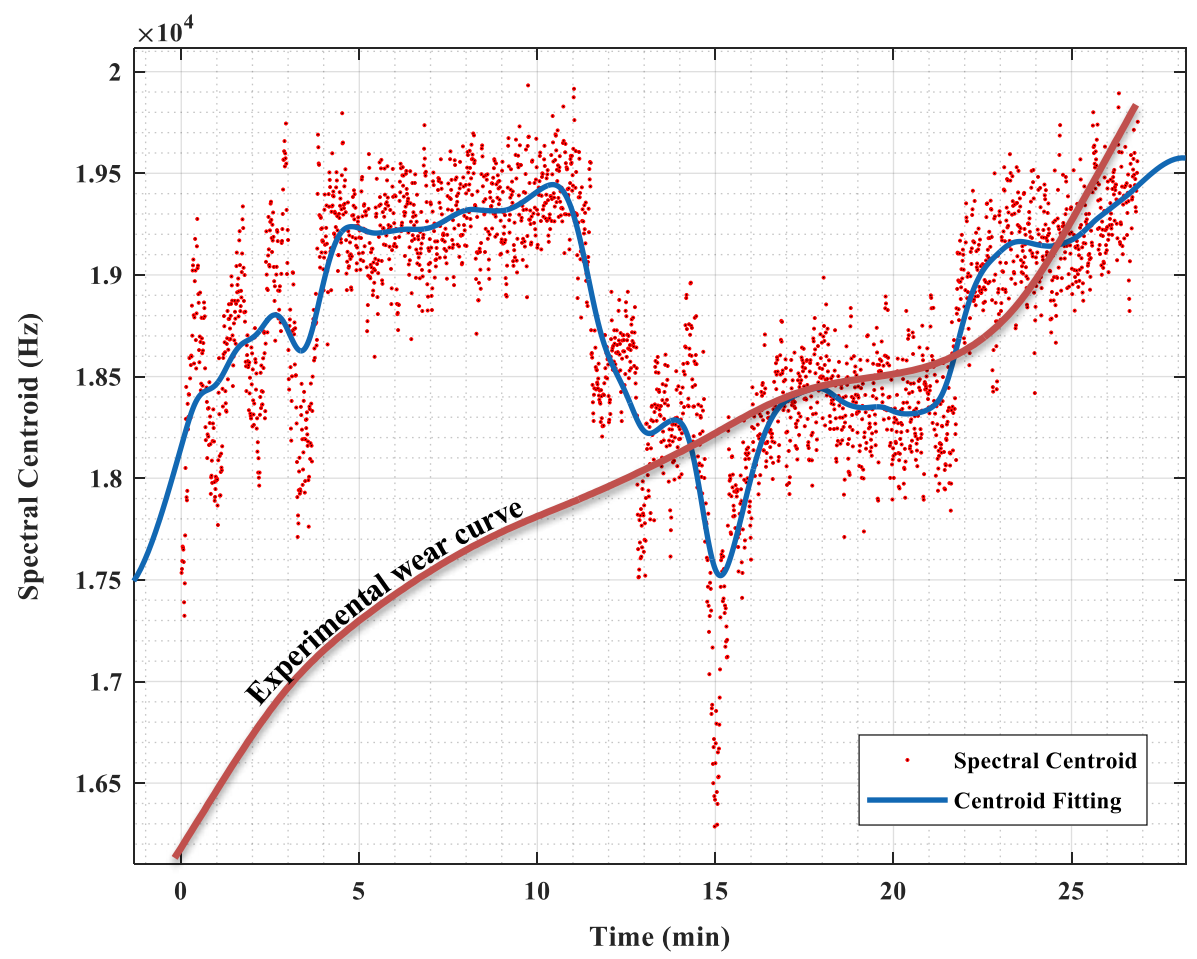

Figure 11. SCI signature during machining time

As shown in Figure 11, the increases in SCI values at the first " $11 \mathrm{~min}$ " are function of the vibration generated by the wear evolution. During the wear stabilization phase, the SCI decreases significantly until the $15^{\text {th }}$ min, this decrease causes a disturbance of the spectral stability due to the state of wear, which is the case for the $9^{\text {th }}$ test with a wear value of $171.818 \mu \mathrm{m}$. (see figure 4), conducting that the wear morphology has an important influence on the vibration behavior.

Arriving at the most severe stage of wear, the SCI indicator has taken the same trend as the experimental wear curve due to the occurrence of serious vibrations that leads to the increase in vibratory energy. which will provide us with more information about this critical phase.

\section{ANN based modeling}

To achieve the current results, several networks have been designed and tested to explore the best architecture, the most suitable activation function, and the best training 
algorithm. The back-propagation algorithm was used as learning algorithm, and the hyperbolic tangent sigmoid transfer function (TANSIG) has been used as activation function. Several network structures were tested, and the ideal networks were found to be a feed forward neural network by 5 hidden layers, where the RMS and the spectral centroid indicator (SCI) have been chosen as input parameters whereas, the target is Flank wear (VB). The performance capability of each network was examined based on the correlation coefficient using the training, validation, and test dataset. The performances of the prediction models of tool wear using the training validation and test dataset for using RMS indicator are shown in Figure 12.
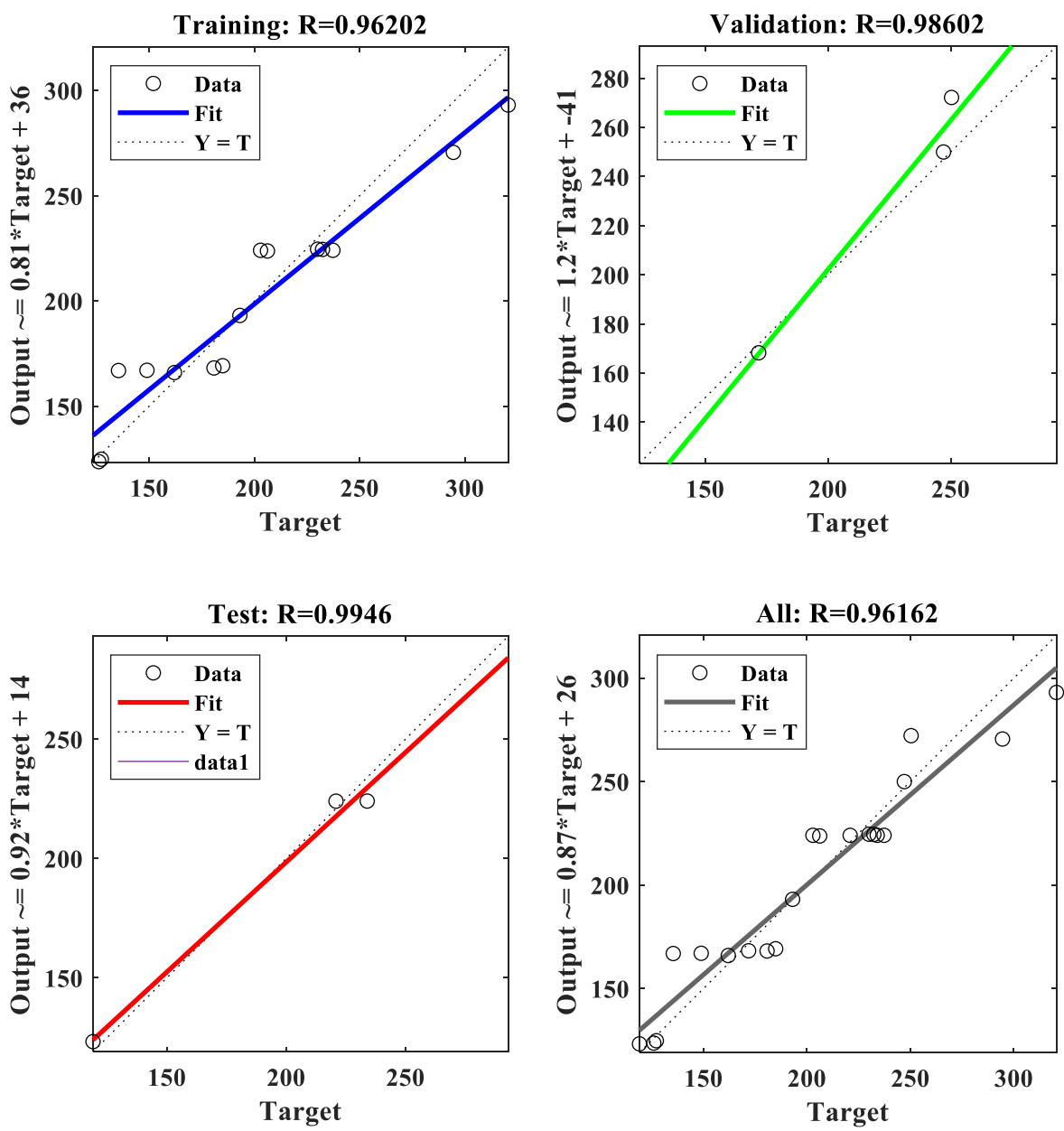

Figure 12. RMS-based Network performance.

The correlation coefficient of the obtained model for this case is $96.162 \%$ as indicated in Figure 12, Despite the fact that the correlation coefficient is initially good (0.96162), but from the prediction results, when taking the case of the tests $\mathrm{N}^{\circ}$ "1", "4", "10" and "19", where the ANN model has over-fitted the data and have not generalize well as indicated in Figure 13, 
this is justified by the number of data used for training, validation and for the test of the current network. And also, the quality of information given by the RMS indicator as regards the wear evolution.

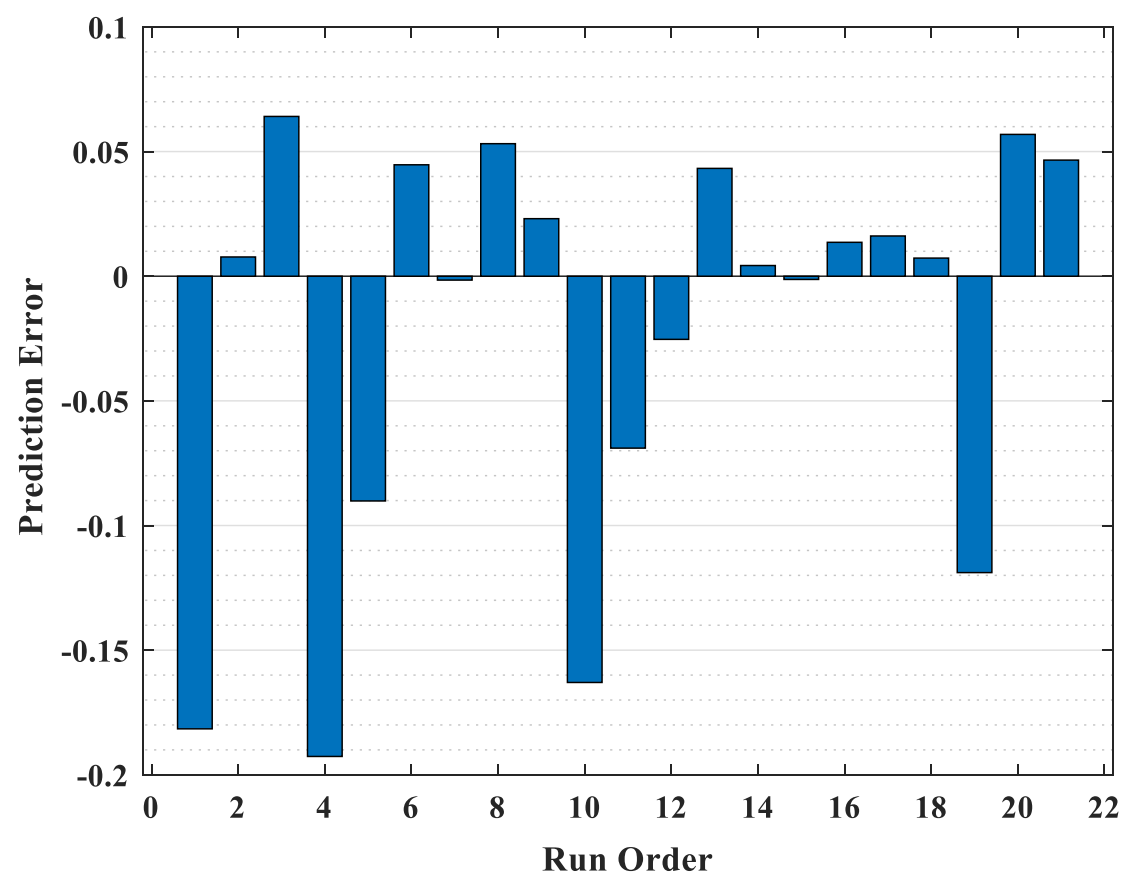

Figure 13. Prediction Error (\%) of RMS-ANN network.

The SCI-based Network performance plots are shown in figure 14. The results are encouraging, and the prediction data presents a good agreement with the experimental values of the flank wear as shown in figures 15 and 16, usually there is substantial variation of the observed points around the fitted regression line, with low prediction error as compared to the case of the RMS-ANN network. 


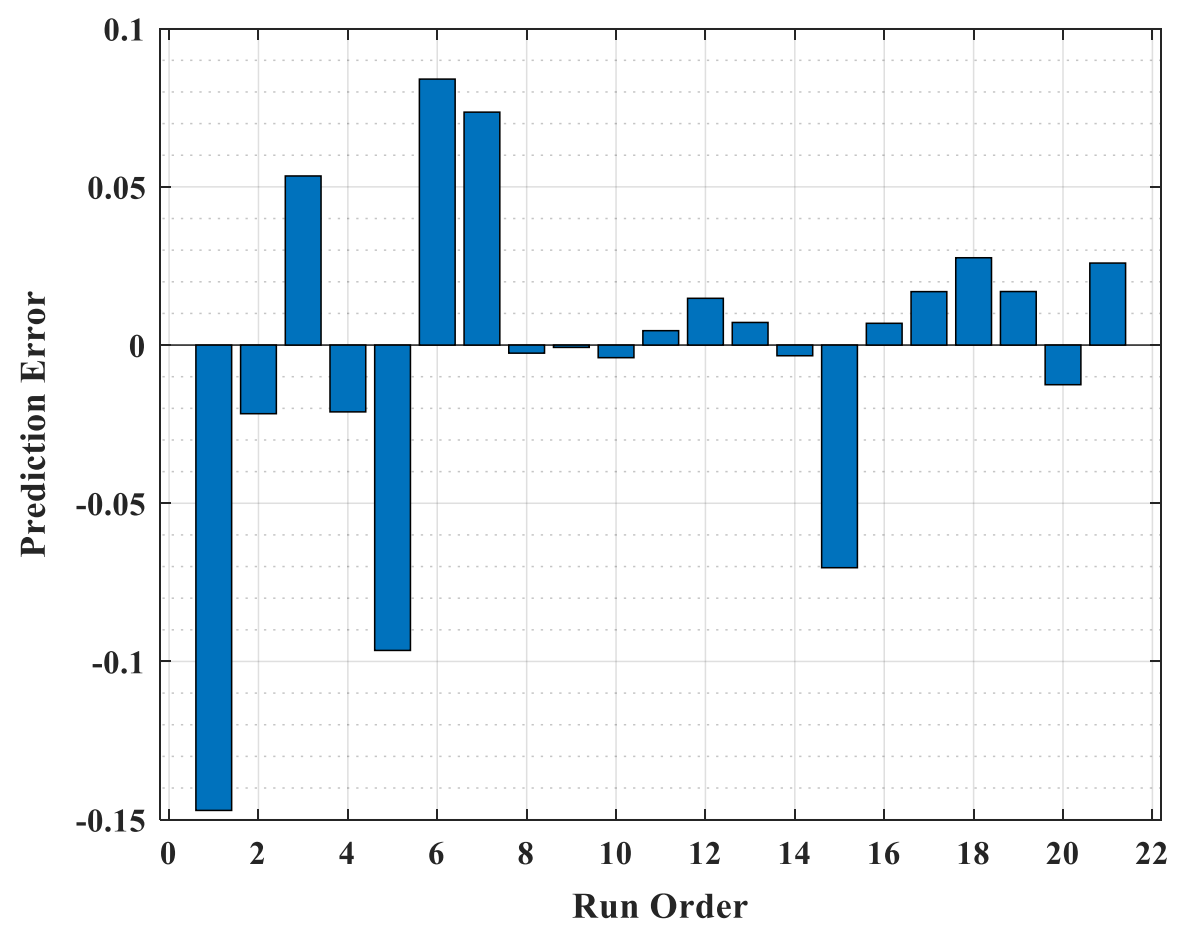

Figure 11. Prediction Error (\%) of the network using RMS Indicator.
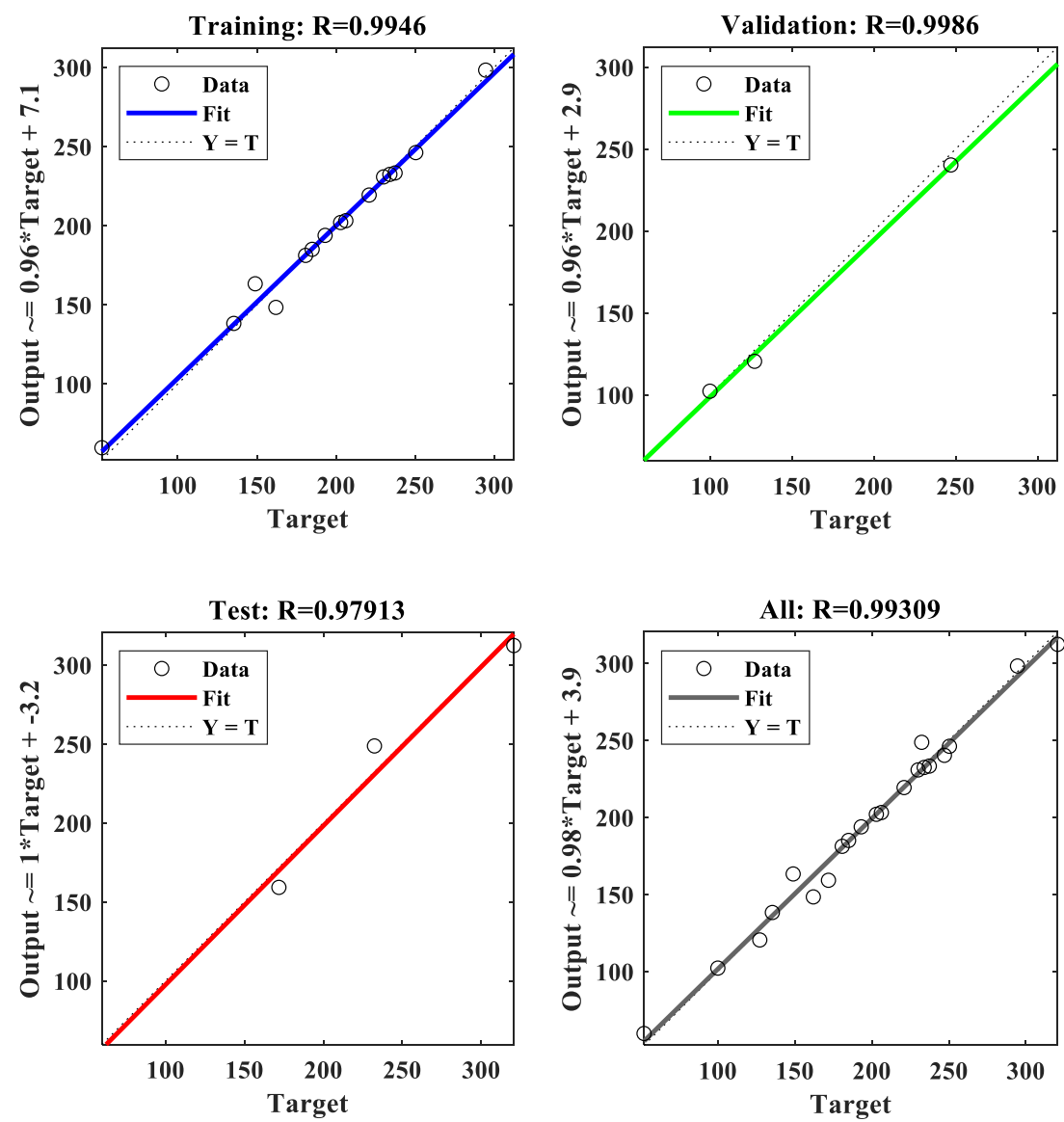

Figure 14. SCI -based Network performance. 


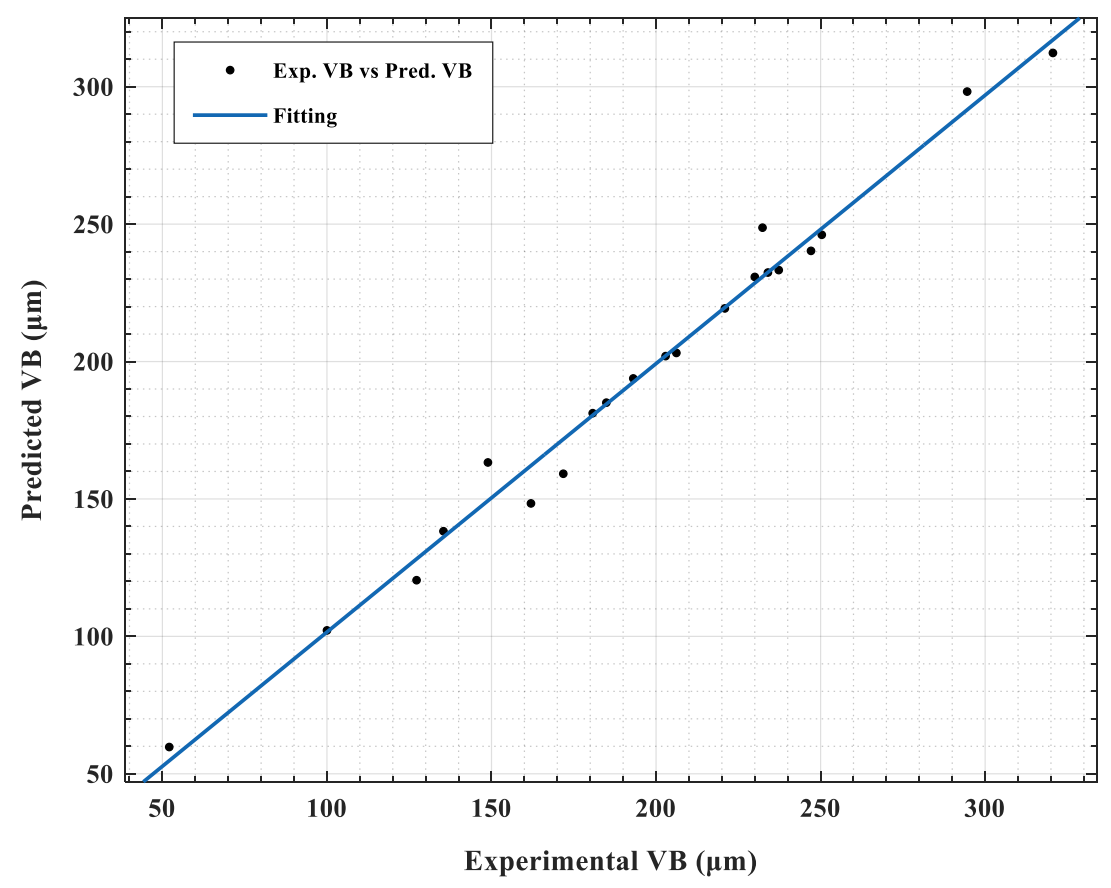

Figure 15. Experimental $V_{B}$ vs Predicted $V_{B}$

\section{Conclusion}

This paper checked the possibility of tool wear and surface roughness monitoring based on vibration analysis. CEEMDAN has been adopted as a decomposition tool that isolate the ideal band which contains the turning process signature. First, Root Mean Square has been calculated for the twenty-one selected IMFs and found to be sensitive during the wear stabilization phase although the researches are interested in the failure phase characterized by wear acceleration. On the other hand, Spectral Centroid Indicator has been in correlation with the wear behavior, SCI values have increased as regard as the wear intensification until the end of initial wear stage. During the wear stabilization phase, the SCI has decreased significantly and caused a disturbance in the spectral stability. Arriving at the most severe stage of wear, the $\mathrm{SCI}$ indicator has taken the same trend as the experimental wear curve due to the occurrence of serious vibrations that have led to an increase in vibratory energy. Therefore, SCI can be used for tool wear stages classification.

The current results have been injected into an artificial neural network in order to predict wear comportment for future online monitoring applications. The prediction accuracy qualifies this tool for insert wear condition identification during turning process.

Laser Doppler Vibrometer (LDV) is an interesting tool that helps for vibration measurement during the machining process even if lubricants are used. 


\section{Acknowledgment}

The machines, devices and tools used in this work, are the property of the Mechanics Research Center of Constantine, the latter is financed by the Algerian Ministry of Higher education and Scientific Research. 


\section{Reference}

[1] Lauro, C. H., Brandão, L. C., Baldo, D., Reis, R. A., \& Davim, J. P. (2014). Monitoring and processing signal applied in machining processes-A review. Measurement, 58, 73-86.

[2] Dimla, D. E. (2002). The correlation of vibration signal features to cutting tool wear in a metal turning operation. The International Journal of Advanced Manufacturing Technology, 19(10), 705-713.

[3] Zeng, S., Wan, X., Li, W., Yin, Z., \& Xiong, Y. (2012). A novel approach to fixture design on suppressing machining vibration of flexible workpiece. International journal of machine tools and manufacture, 58, 29-43.

[4] Devillez, A., \& Dudzinski, D. (2007). Tool vibration detection with eddy current sensors in machining process and computation of stability lobes using fuzzy classifiers. Mechanical systems and signal processing, 21(1), 441-456.

[5] Shahabi, H. H., and M. M. Ratnam. "On-line monitoring of tool wear in turning operation in the presence of tool misalignment." The International Journal of Advanced Manufacturing Technology 38.7-8 (2008): 718-727.

[6] Oo, H., Wang, W., \& Liu, Z. (2020). Tool wear monitoring system in belt grinding based on image-processing techniques. The International Journal of Advanced Manufacturing Technology, 111(7), 2215-2229.

[7] Hsieh, Wan-Hao, Ming-Chyuan Lu, and Shean-Juinn Chiou. "Application of backpropagation neural network for spindle vibration-based tool wear monitoring in micro-milling." The International Journal of Advanced Manufacturing Technology 61.1-4 (2012): 53-61.

[8] Babouri, M. K., Ouelaa, N., Djebala, A., Djamaa, M. C., \& Boucherit, S. (2017). Prediction of cutting tool's optimal lifespan based on the scalar indicators and the wavelet multi-resolution analysis. In Applied Mechanics, Behavior of Materials, and Engineering Systems (pp. 299-310). Springer, Cham.

[9] Babouri, M. K., Ouelaa, N., Djamaa, M. C., Djebala, A., \& Hamzaoui, N. (2017). Prediction of tool wear in the turning process using the spectral center of gravity. Journal of Failure Analysis and Prevention, 17(5), 905-913.

[10] Rao, K. V., Murthy, B. S. N., \& Rao, N. M. (2013). Cutting tool condition monitoring by analyzing surface roughness, work piece vibration and volume of metal removed for AISI 1040 steel in boring. Measurement, 46(10), 4075-4084. 
[11] Abu-Mahfouz, I. (2003). Drilling wear detection and classification using vibration signals and artificial neural network. International Journal of Machine Tools and Manufacture, 43(7), 707-720.

[12] Du, M., Wang, P., Wang, J., Cheng, Z., \& Wang, S. (2019). Intelligent Turning Tool Monitoring with Neural Network Adaptive Learning. Complexity, 2019.

[13] Xu, X., Wang, J., Ming, W., Chen, M., \& An, Q. (2021). In-process tap tool wear monitoring and prediction using a novel model based on deep learning. The International Journal of Advanced Manufacturing Technology, 112(1), 453-466.

[14] Wang, Xiaoyu, et al. "Design of neural network-based estimator for tool wear modeling in hard turning." Journal of intelligent manufacturing 19.4 (2008): 383-396.

[15] Purushothaman, Srinivasan. "Tool wear monitoring using artificial neural network based on extended Kalman filter weight updation with transformed input patterns." Journal of Intelligent Manufacturing 21.6 (2010): 717-730.

[16] Sharma, Vishal S., S. K. Sharma, and Ajay K. Sharma. "Cutting tool wear estimation for turning." Journal of Intelligent Manufacturing 19.1 (2008): 99-108.

[17] Aghdam, B. H., M. Vahdati, and M. H. Sadeghi. "Vibration-based estimation of tool Major Flank wear in a turning process using ARMA models." The International Journal of Advanced Manufacturing Technology 76.9-12 (2015): 1631-1642.

[18] Liu, H., Mi, X., \& Li, Y. (2018). Comparison of two new intelligent wind speed forecasting approaches based on wavelet packet decomposition, complete ensemble empirical mode decomposition with adaptive noise and artificial neural networks. Energy Conversion and Management, 155, 188-200.

[19] Nouioua, M., Yallese, M. A., Khettabi, R., Chabbi, A., Mabrouki, T., \& Girardin, F. (2017, March). Optimization of Machining Process During Turning of X210Cr12 Steel Under MQL Cooling as a Key Factor in Clean Production. In International Conference Design and Modeling of Mechanical Systems (pp. 855-863). Springer, Cham.

[20] Elbah, M., Laouici, H., Benlahmidi, S., Nouioua, M., \& Yallese, M. A. (2019). Comparative assessment of machining environments (dry, wet and MQL) in hard turning of AISI 4140 steel with CC6050 tools. The International Journal of Advanced Manufacturing Technology, 105(5), 2581-2597. 
[21] Nouioua, M., Yallese, M. A., Khettabi, R., Belhadi, S., \& Mabrouki, T. (2017). Comparative assessment of cooling conditions, including MQL technology on machining factors in an environmentally friendly approach. The International Journal of Advanced Manufacturing Technology, 91(9), 3079-3094.

[22] Nouioua, M., Yallese, M. A., Khettabi, R., Belhadi, S., Bouhalais, M. L., \& Girardin, F. (2017). Investigation of the performance of the MQL, dry, and wet turning by response surface methodology (RSM) and artificial neural network (ANN). The International Journal of Advanced Manufacturing Technology, 93(5), 2485-2504.

[24] Igba, J., Alemzadeh, K., Durugbo, C., \& Eiriksson, E. T. (2016). Analysing RMS and peak values of vibration signals for condition monitoring of wind turbine gearboxes. Renewable Energy, 91, 90-106.

[24] Krimphoff, J., McAdams, S., \& Winsberg, S. (1994). Caractérisation du timbre des sons complexes. II. Analyses acoustiques et quantification psychophysique. Le Journal de Physique IV, 4(C5), C5-625. 


\section{Déclarations}

Funding: The work is financed by the Algerian Ministry of Higher education and Scientific Research.

Conflicts of interest/Competing interests: I, Doctor Mourad NOUIOUA, corresponding author of the paper, certify that we have no potential conflict of interest for the presented article Availability of data and material: Not applicable

Code availability: Not applicable

Authors' contributions: (optional)

Additional declarations for articles in life science journals that report the results of studies involving humans and/or animals: Not applicable

Ethics approval: I certify that the paper follows the ethical rules of good scientific practice mentioned in the "Ethical Responsibilities of Authors" of the journal.

Consent to participate (include appropriate statements): Not applicable

Consent for publication (include appropriate statements)

Mourad NOUIOUA hereby declare that I participated in the study and in the development of the manuscript titled (Vibration-based tool wear monitoring using Artificial Neural Networks fed by Spectral centroid indicator \& RMS of CEEMDAN modes) and authorize the full the publishing of manuscript data. 
Figures

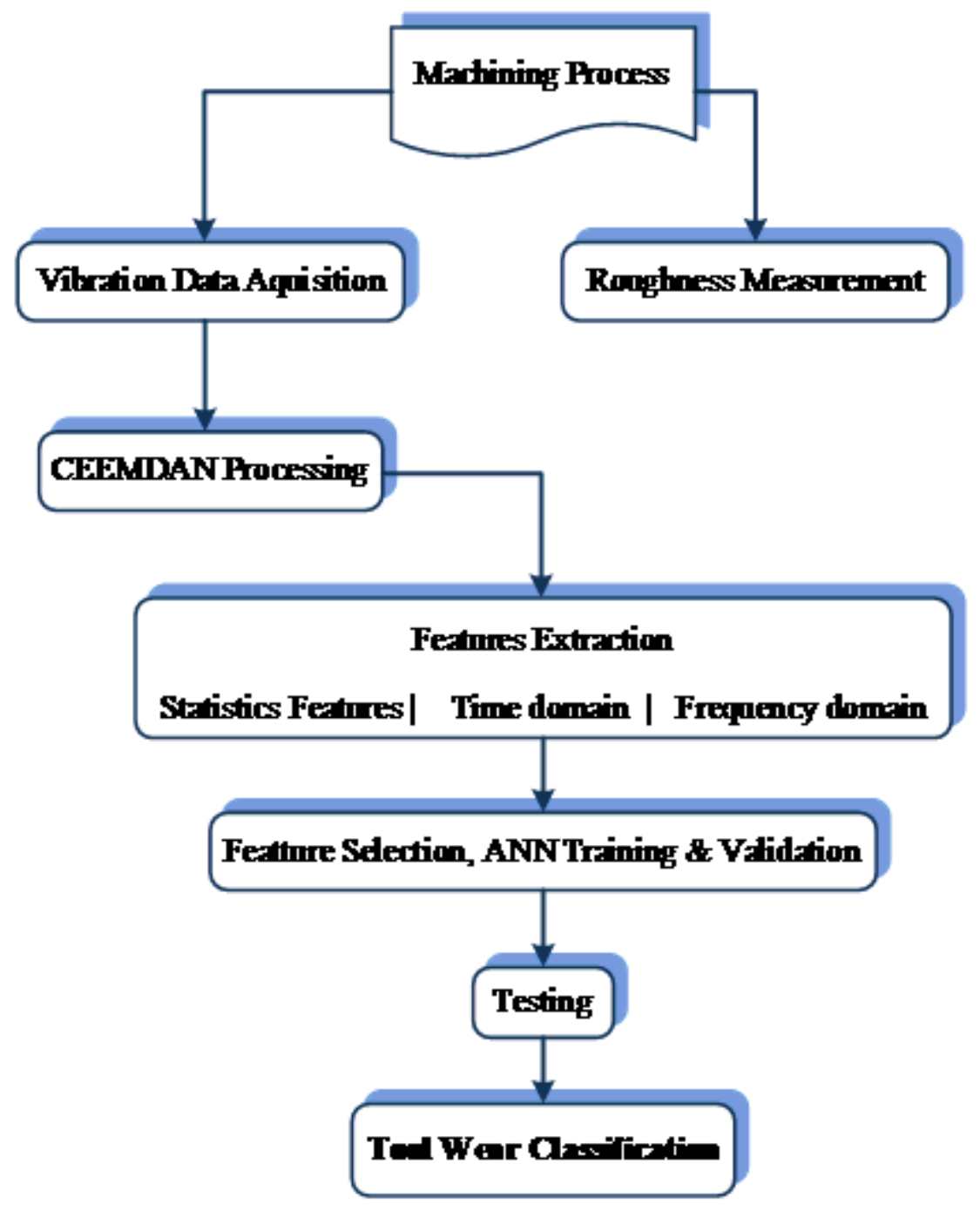

Figure 1

Flow chart of the tool life monitoring method. 


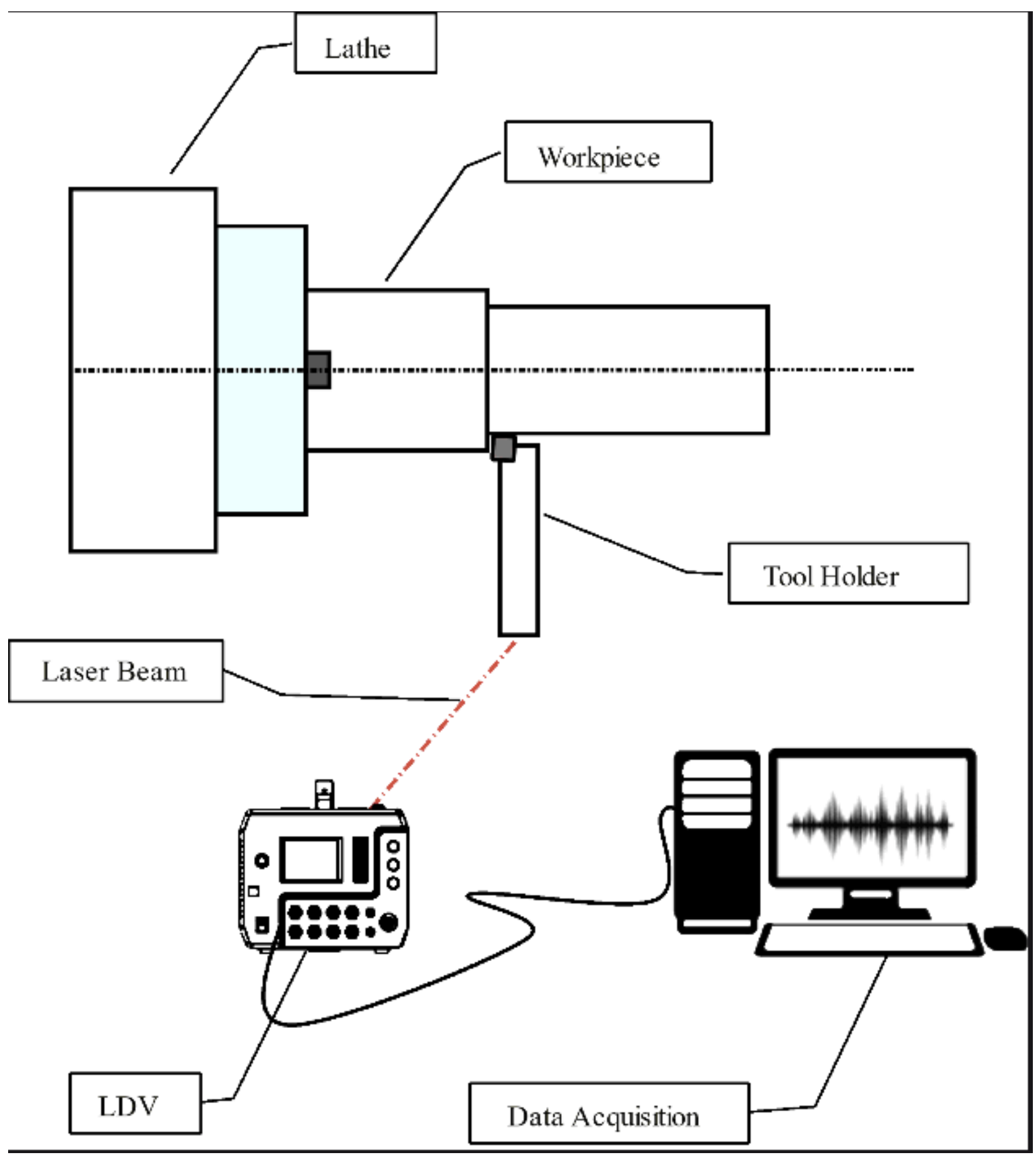

Figure 2

Experimental set up for monitoring system and data analysis. 


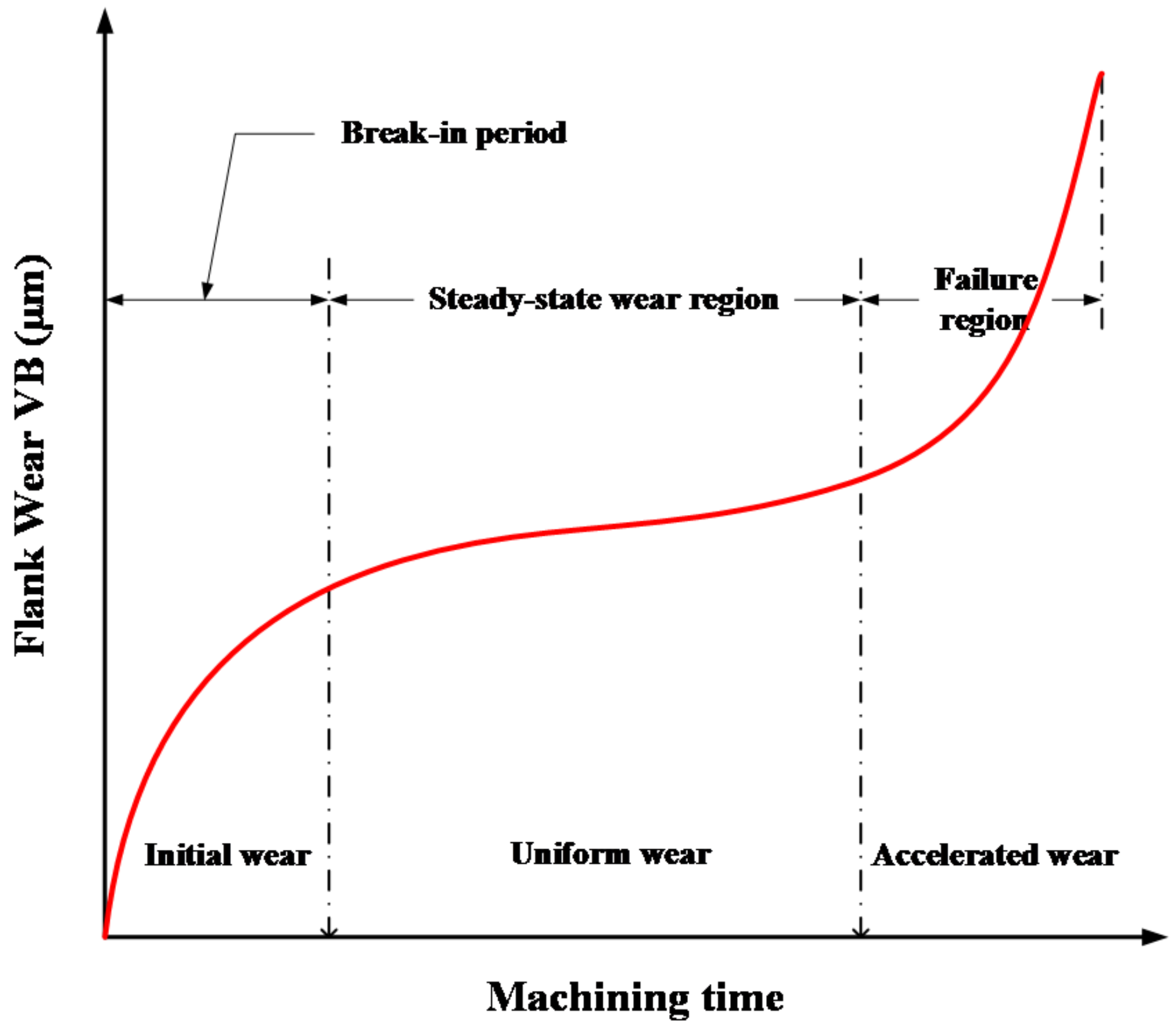

Figure 3

Theoretical tool wear. 

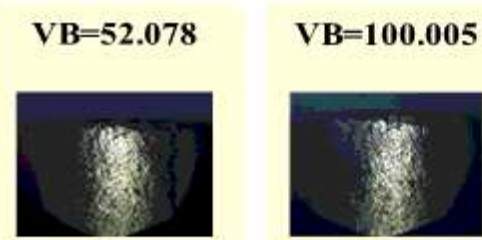

$V B=127.234$

$V B=135.4$

$V B=148.911$

$V B=161.992$
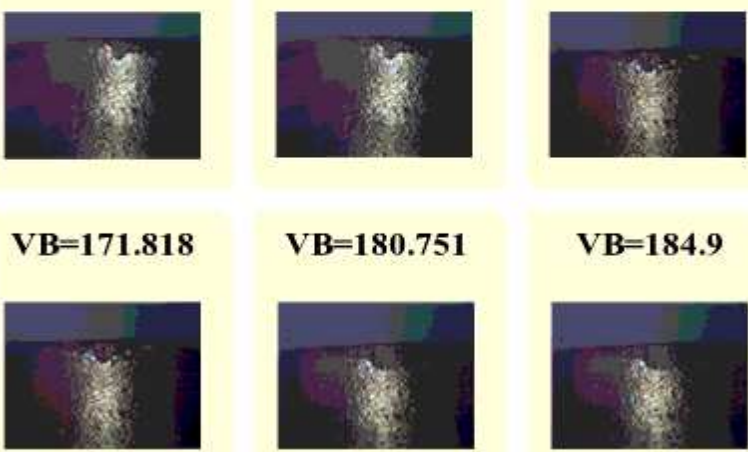

$V B=180.751$

$\mathrm{VB}=184.9$
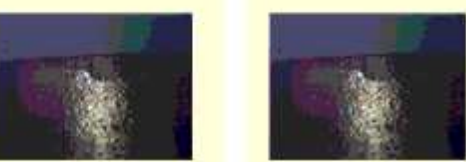

$V B=193.082$

$V B=202.9$

$V B=206.179$
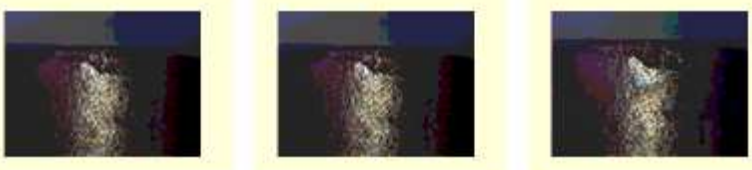

$V B=220.905$

$V B=230.006$

$V B=232.353$
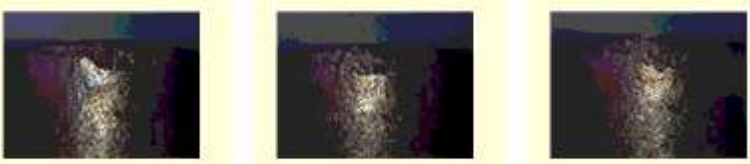

$V B=233.989$

$V B=237.284$

$V B=247.085$
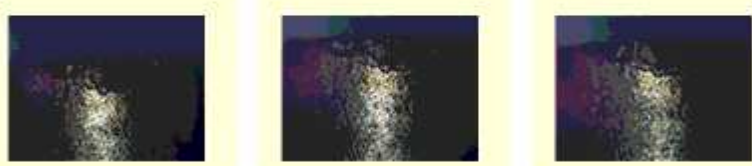

$V B=250.357$

$V B=294.536$

$V B=320.594$
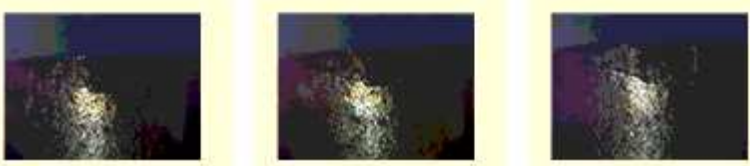

Figure 4

Wear Morphology from test of the cutting insert. 


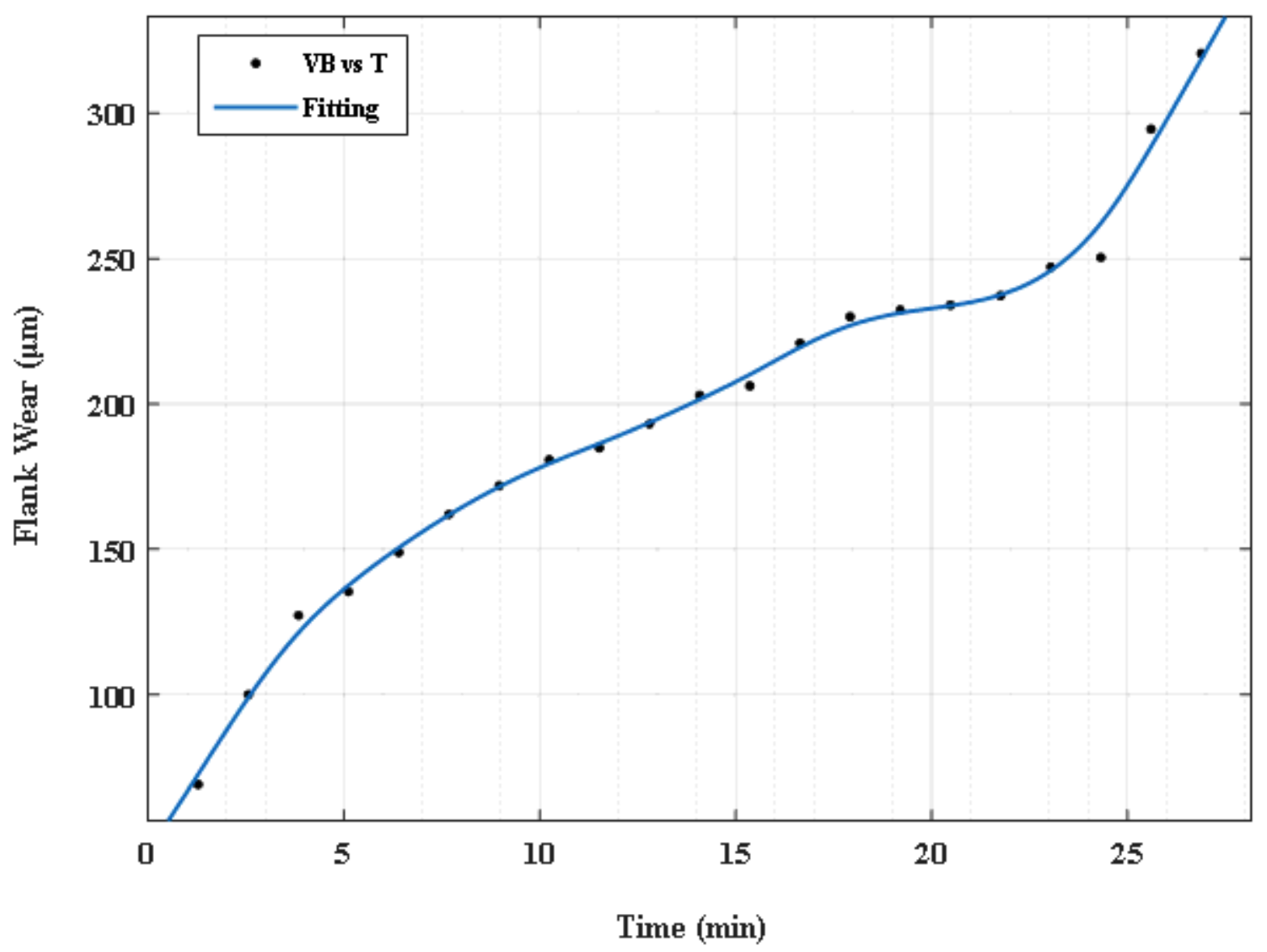

Figure 5

Wear Evolution Vs machining time 


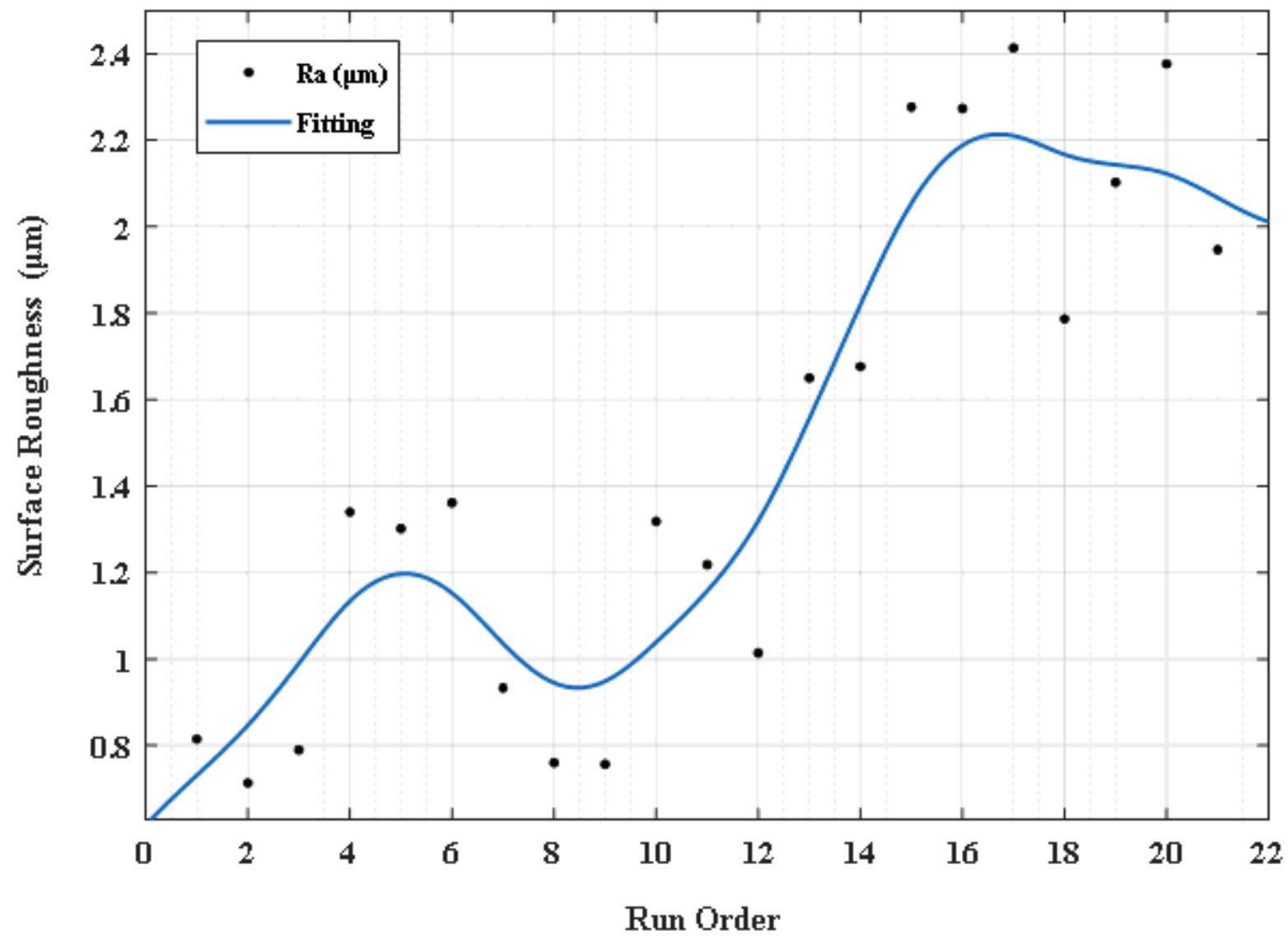

Figure 6

Surface roughness Vs. experimental run order 


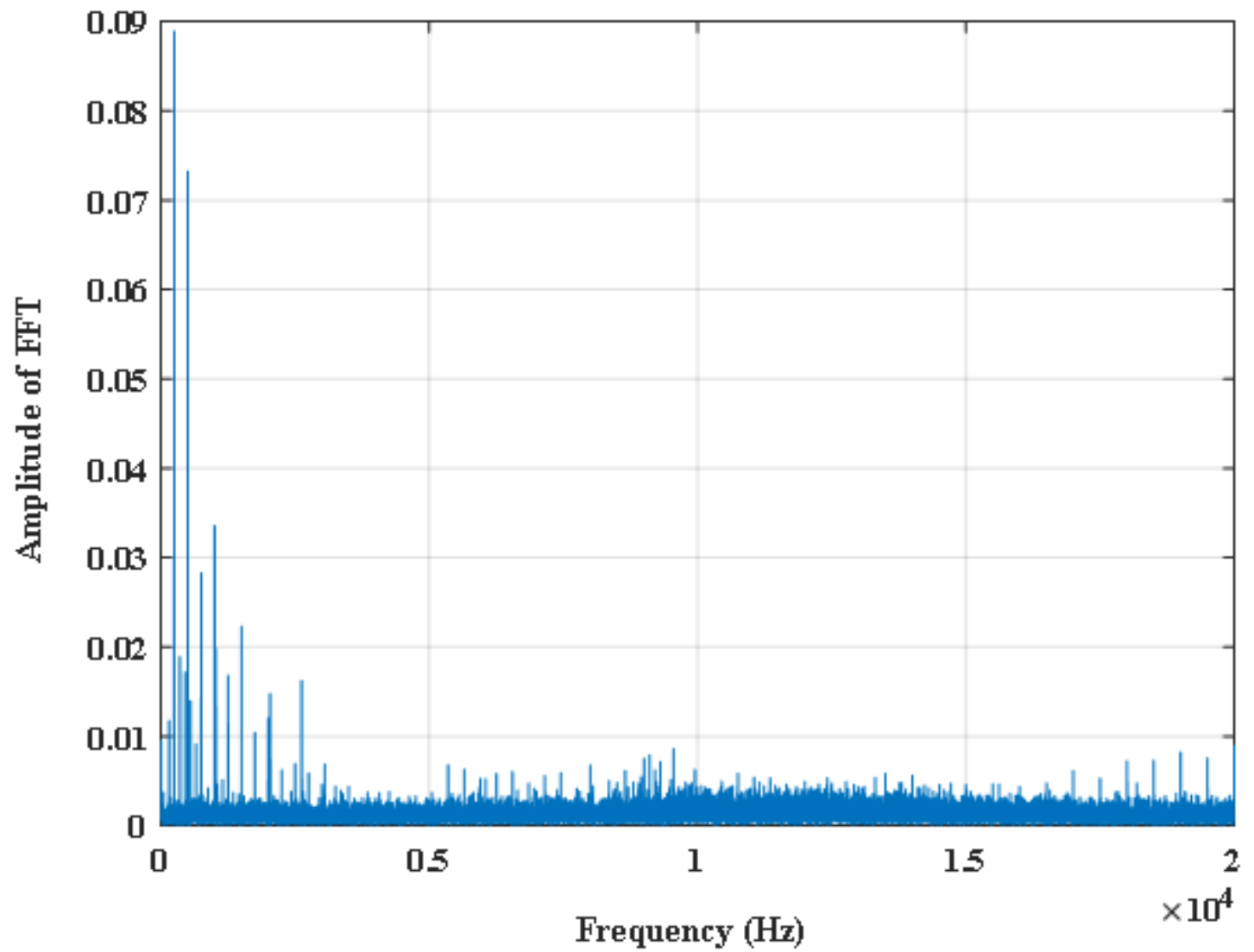

Figure 7

Free run spectrum. 

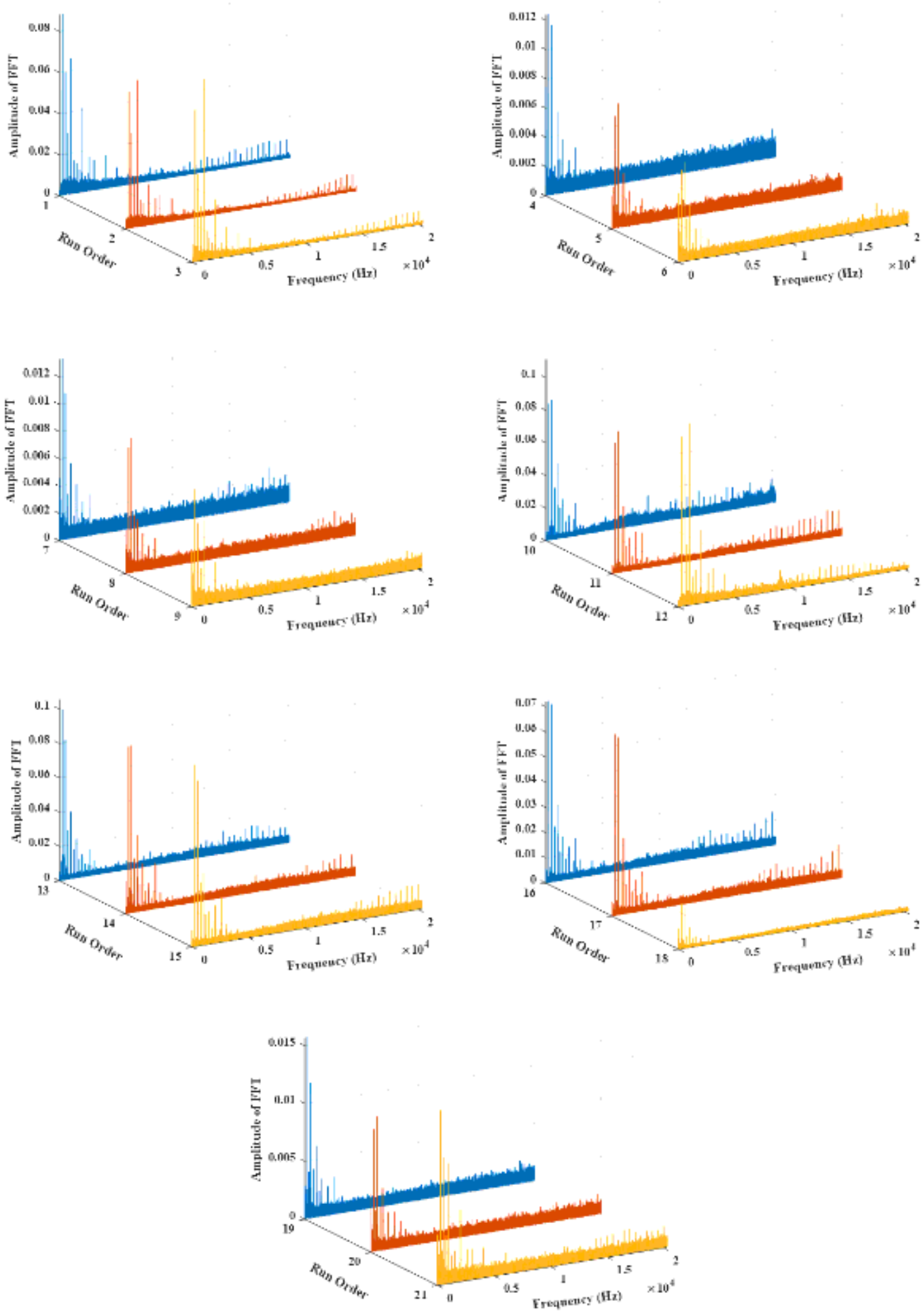

Figure 8

Autospectrum of the twenty-one runs. 


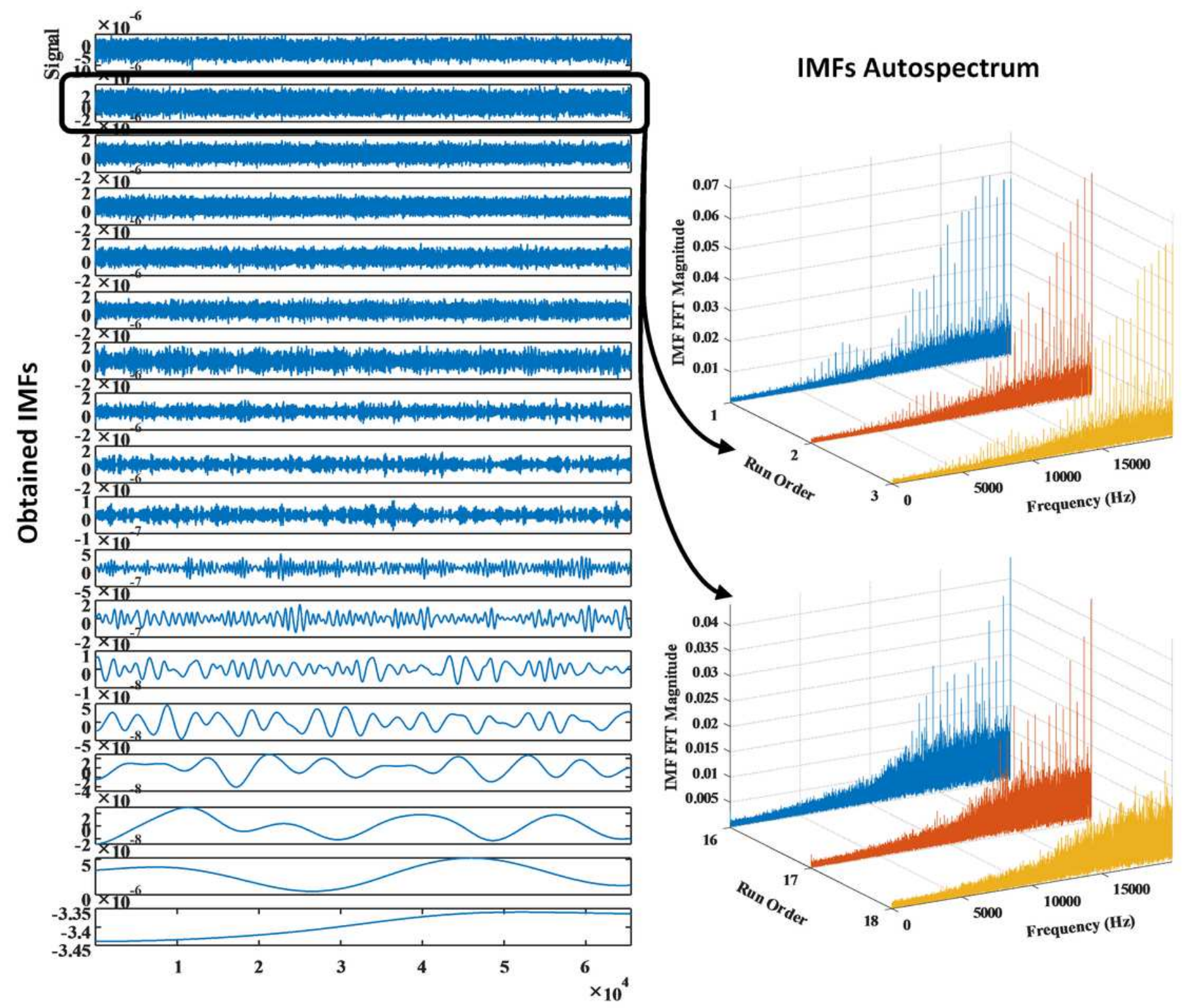

Figure 9

CEEMDAN decomposition. 


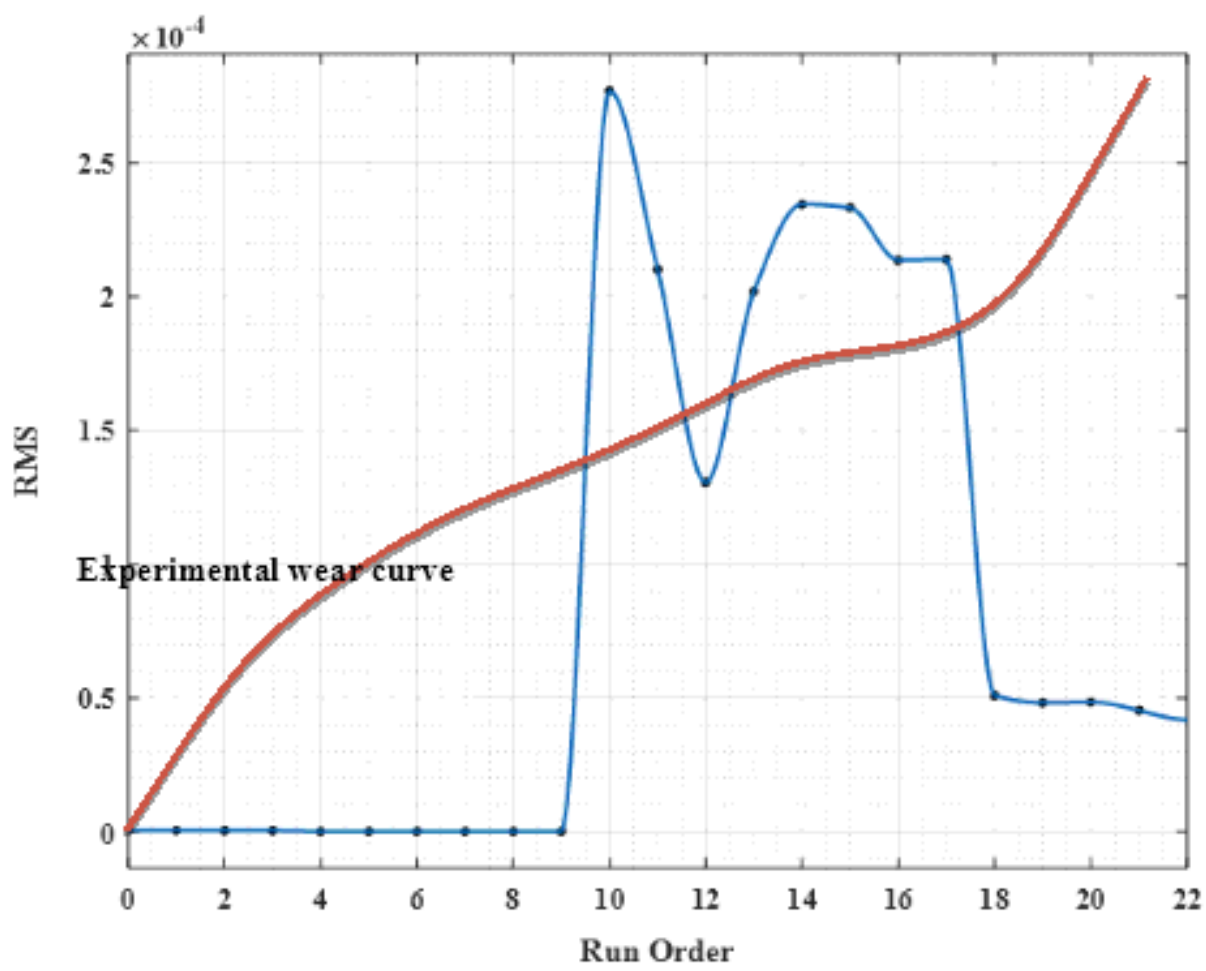

Figure 10

Obtained RMS for the twenty-one signals.

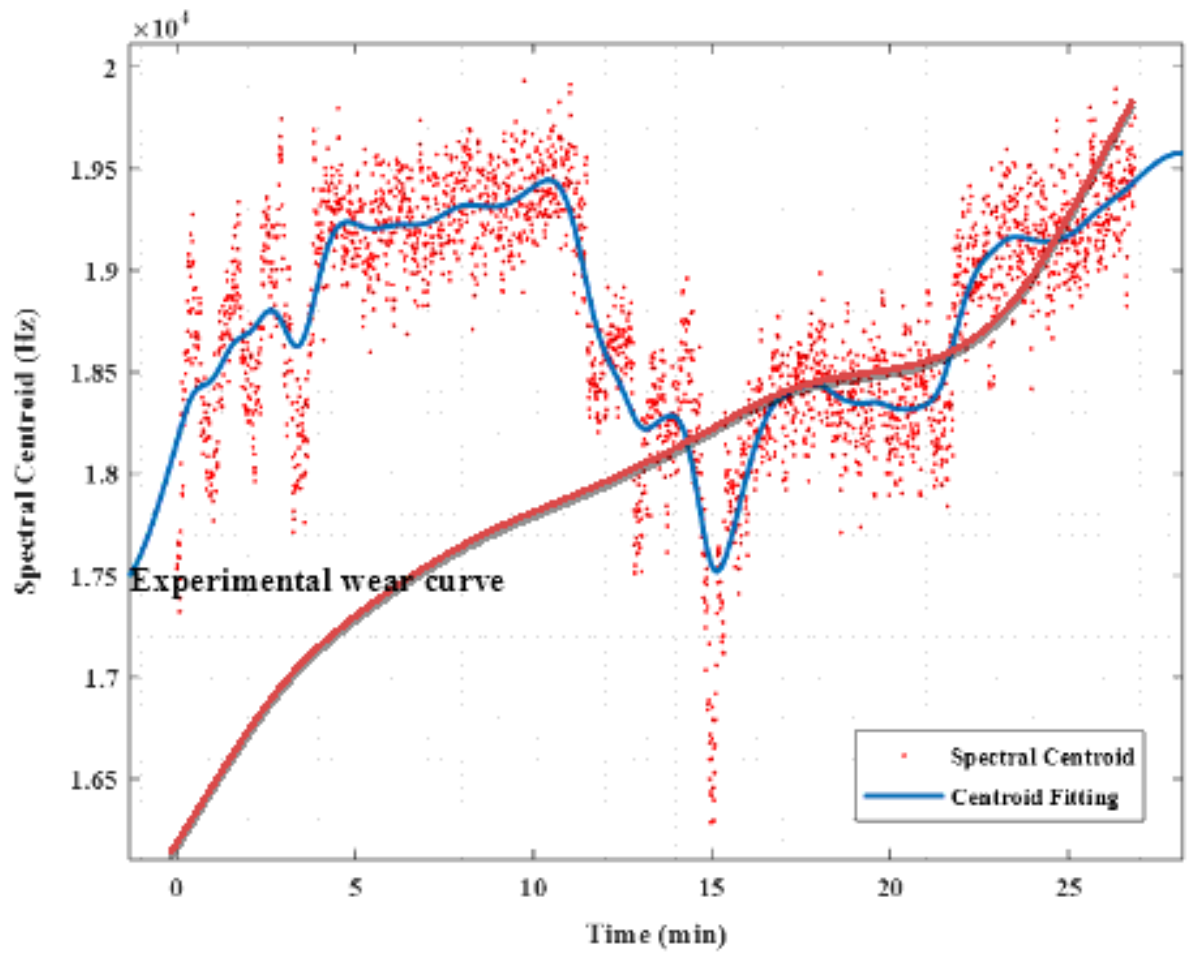

Figure 11

$\mathrm{SCl}$ signature during machining time 

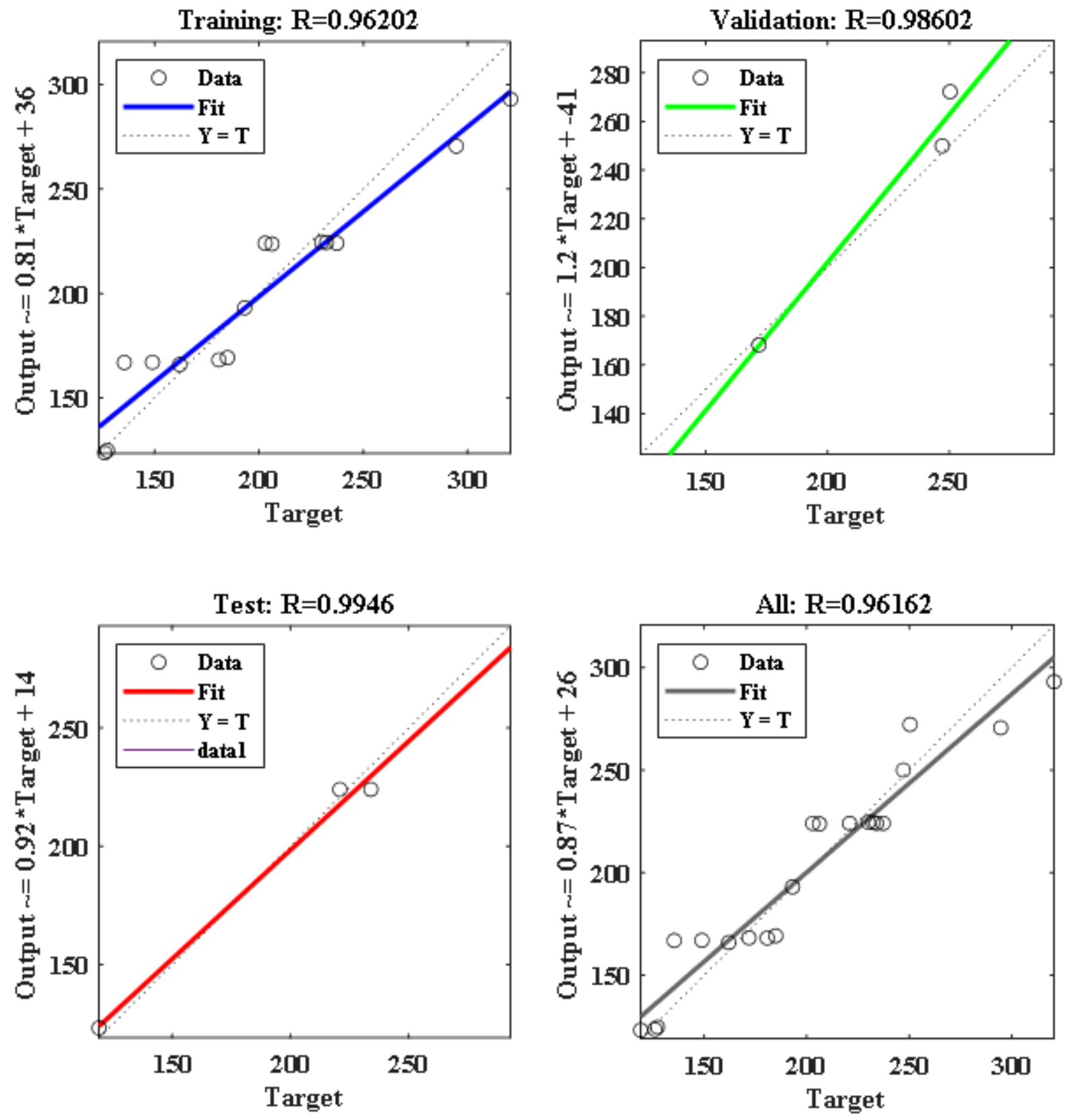

Figure 12

RMS-based Network performance. 


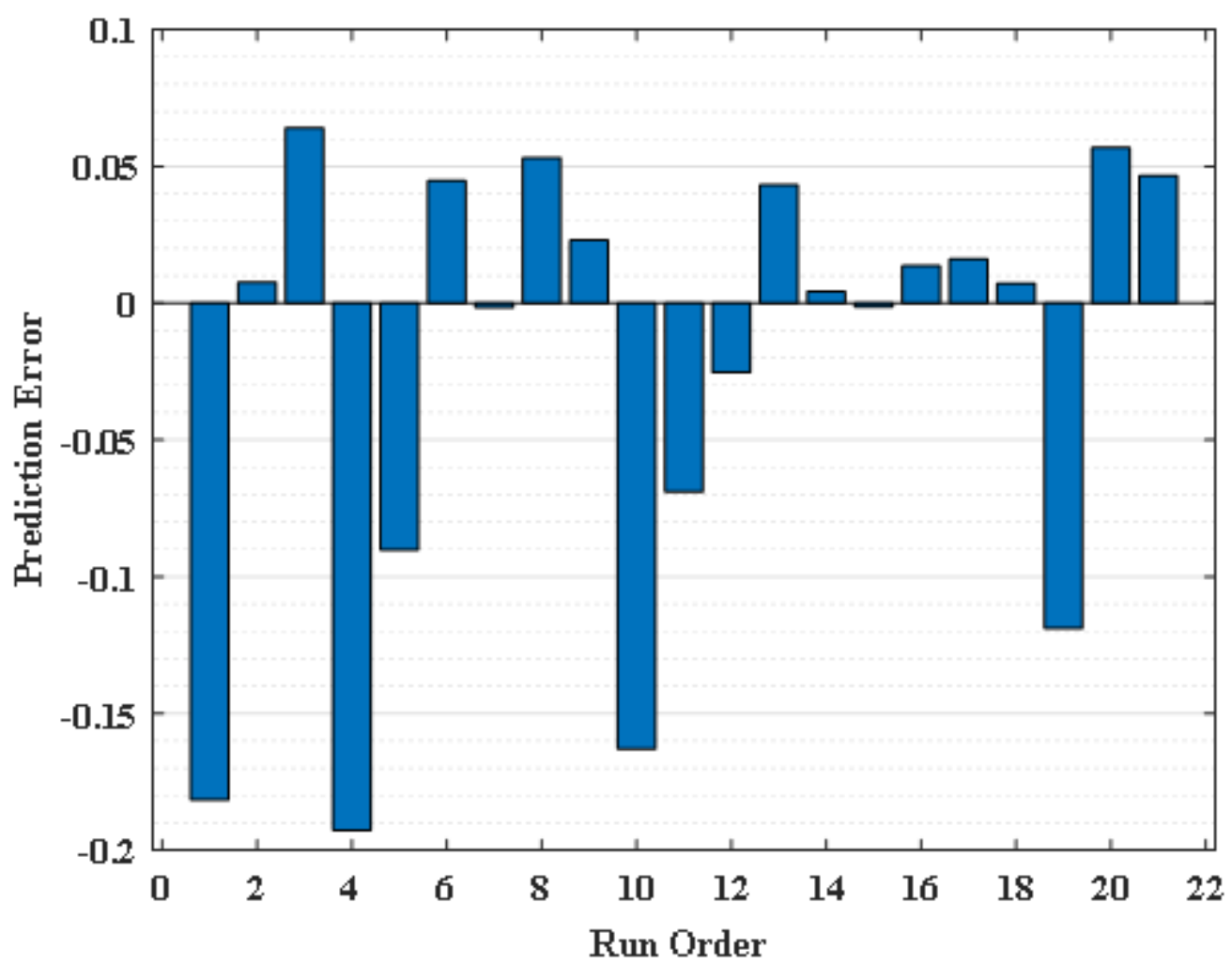

Figure 13

Prediction Error (\%) of RMS-ANN network.

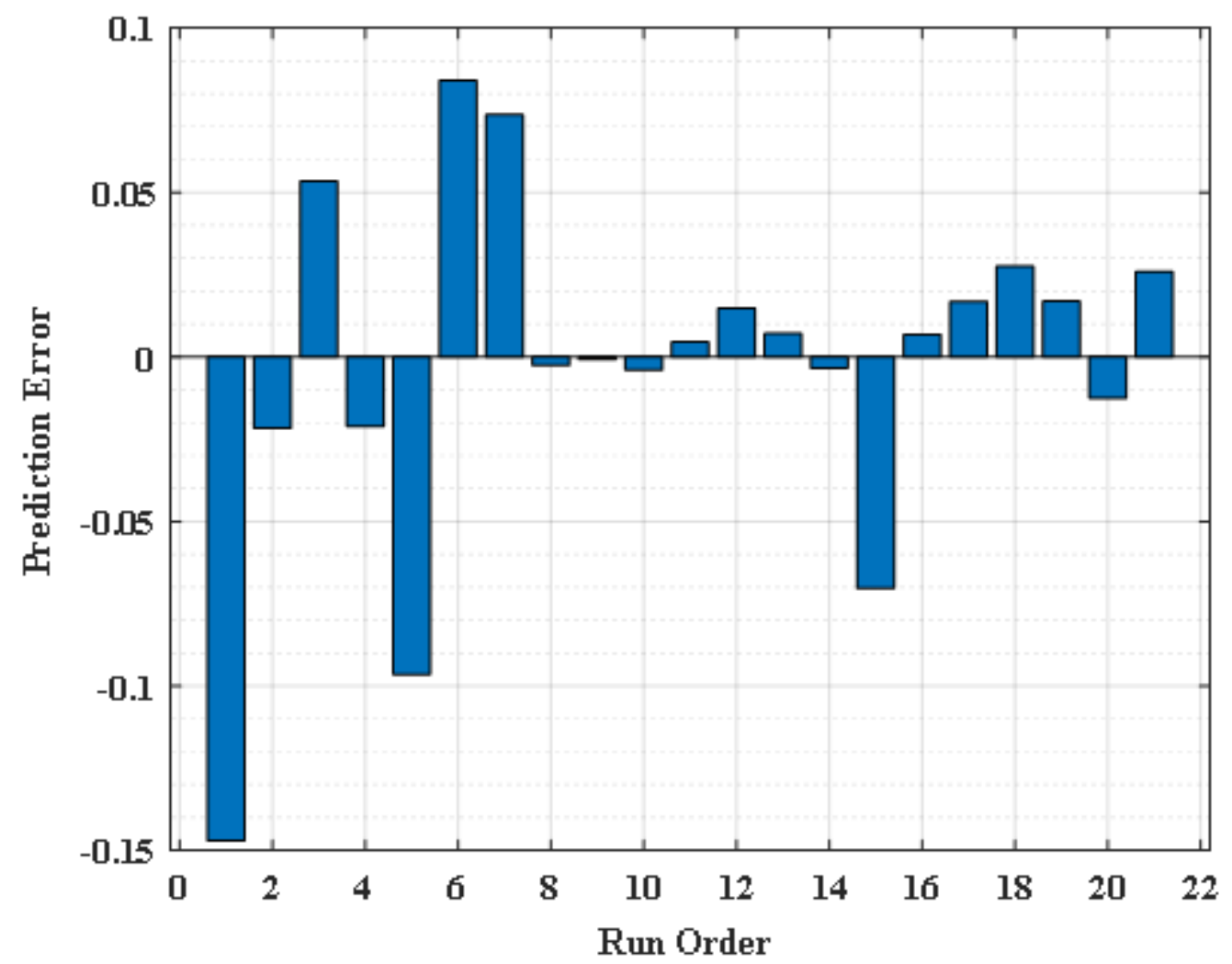


Figure 14

Prediction Error (\%) of the network using RMS Indicator.
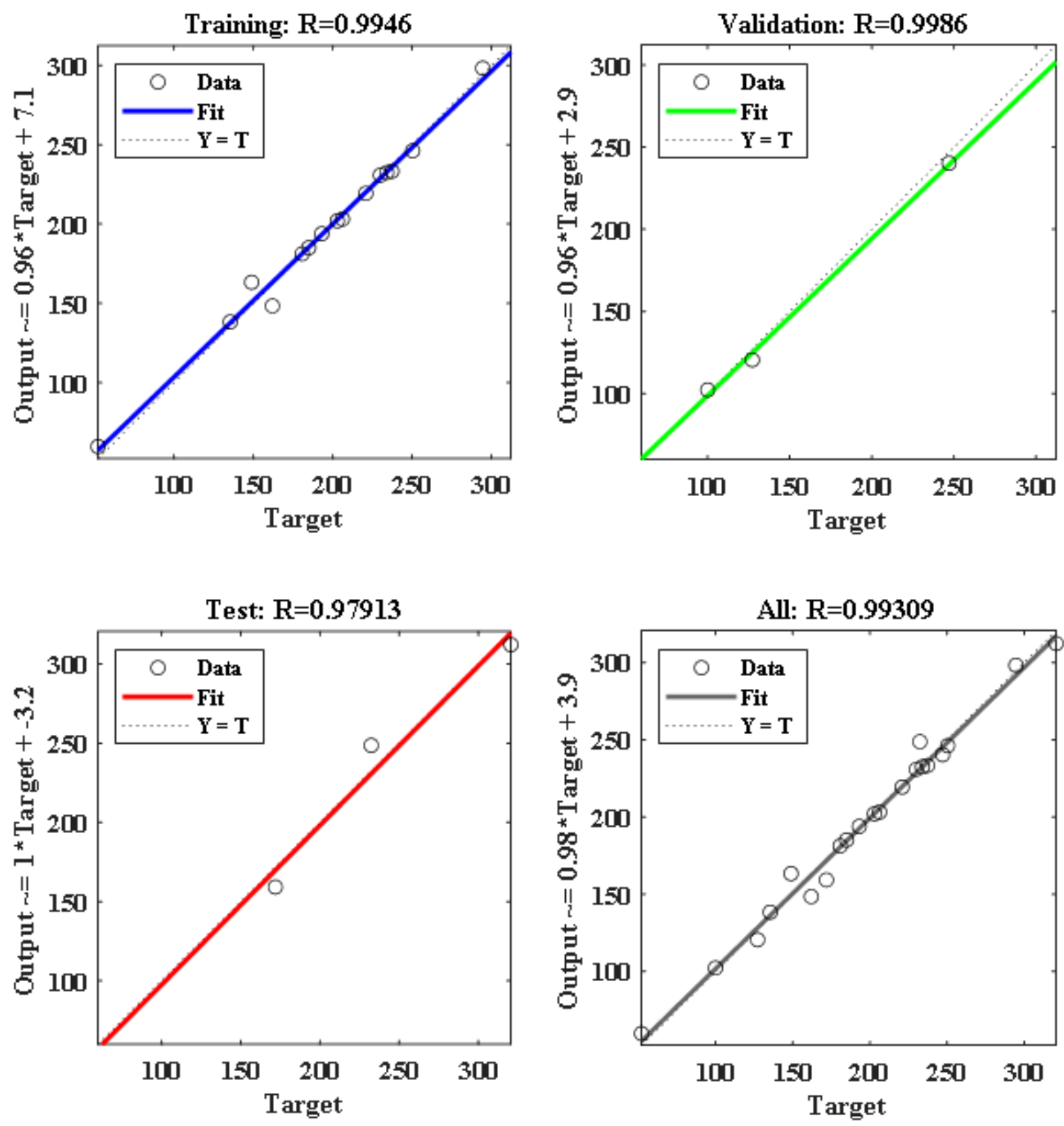

Figure 15

$\mathrm{SCl}$-based Network performance. 


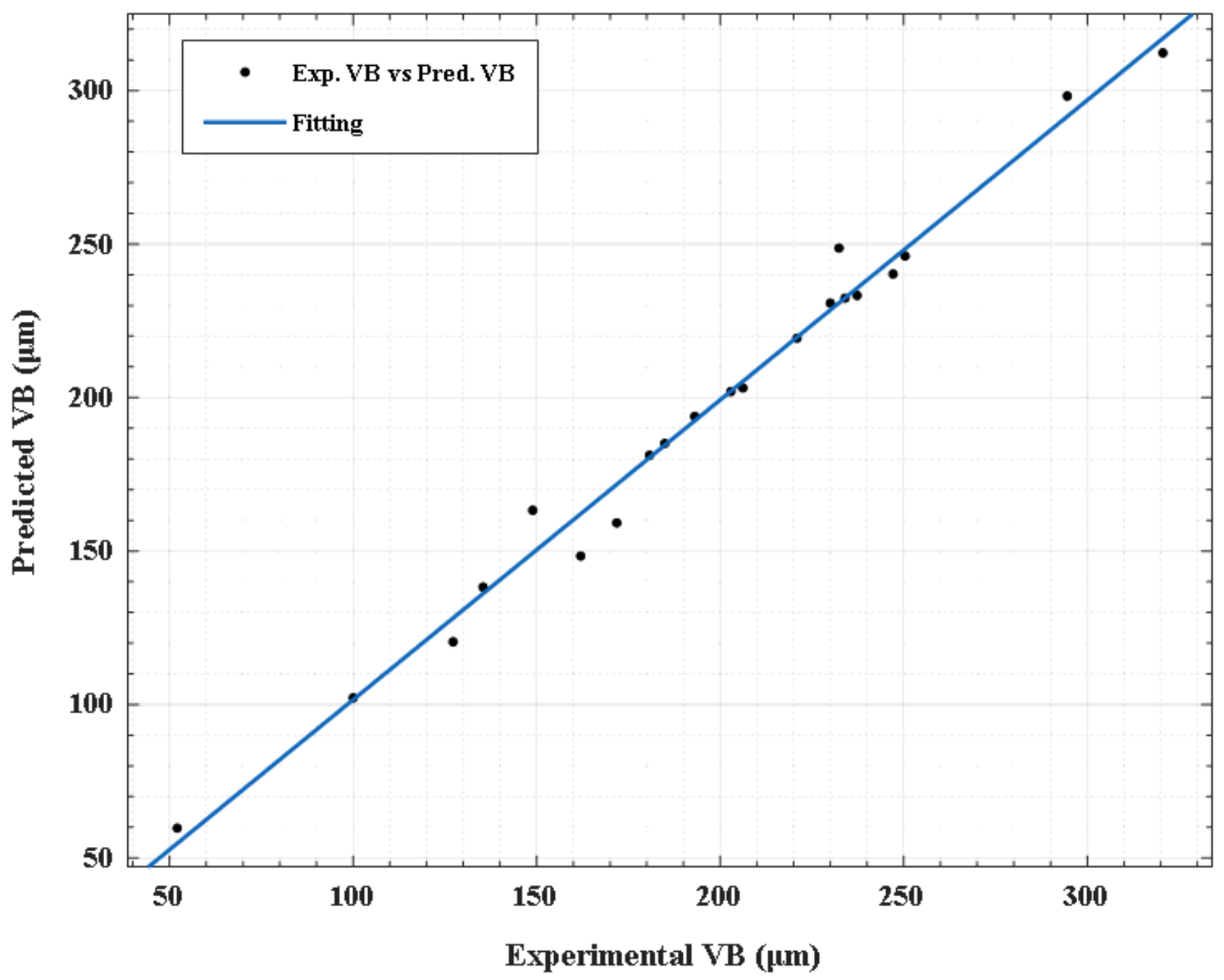

Figure 16

Experimental VB vs Predicted VB 